\title{
MUJERES INDÍGENAS GUARANÍES Y POLÍTICA EN EL SUR AMERINDIO
}

\author{
CLAUDIA CÁCERES GONZÁLEZ1 \\ UNIVERSIDAD DE SALAMANCA, ESPANHA \\ HERNÁN VENEGAS MARCELO ${ }^{2}$ \\ UNILA, BRASIL
}

CRISTINA JENARO RÍO ${ }^{3}$

UNIVERSIDAD DE SALAMANCA, ESPANHA

\begin{abstract}
RESUMEN: Este articulo estudia la participación de las mujeres indigenas en la politica de paises del Cono Sur de América. Tal realidad evidencia empoderamiento de derechos humanos y ejercicio del liderazgo político más allá del espacio comunitario de indígenas en países como Argentina, Bolivia, Brasil y Paraguay, con significativa presencia de pueblos guaranies. Ese proceso no es de interés privativo a un área del conocimiento pues remite a múltiples interfaces en el campo de los estudios indígenas. Así, estudios provenientes de la historia, de la antropología, de la etnografía y de la politología - con miradas desde el Sur, constituyen el fundamento teórico-metodológico del presente artículo. Técnicas de observación participante, entrevistas in loco en comunidades indigenas sustentan las principales ideas de este trabajo que además posee un espíritu comparativo. Desde el punto de vista práctico, se espera que este artículo genere diálogos académicos en pos de una mejor comprensión de la multiculturalidad de las sociedades amerindias y, sobre todo, re-orientar las atenciones en ambientes académicos iberoamericanos a las interfaces entre política, historia y mujeres indígenas.
\end{abstract}

PALABRAS-CLAVE: mujeres indigenas, guaranies, politica, Sur Amerindio.

ABSTRACT: This article studies the involvement of indigenous women in politics in the American Southern Cone countries. The aknoledgement of this fact highlights the empowerment of human rights and political leadership beyond the indigenous community space in countries with significant Guarani populations such as Paraguay, Bolivia, Argentina and Brazil. This process is not of private interest to the study of a certain area of knowledge because its study refers to multiple interfaces in the field of indigenous studies. Therefore, studies of history, anthropology, ethnography and political science - above all with views from the South, are the theoretical and methodological basis of the present work. Participant observation techniques, onsite interviews at indigenous communities support the main ideas of this work, which also has a comparative spirit. From a practical point of view, it is expected that this work provides dialogues aiming at a better understanding of the multiculturality of Amerindian societies and, above all, to draw attention in the academic field to the interfaces among politics, history and indigenous women.

KEYWORDS: indigenous women, politics, Guarani, South Amerindian

\footnotetext{
${ }^{1}$ Doctoranda en Psicología (Universidad de Salamanca, España) e investigadora (Universidad Nacional de Itapúa, Paraguay). E-mail: claudia_caceres@usal.es

2 Profesor del área de Historia y del Posgrado en Historia y en Estudios Latinoamericanos (Universidad Federal da Integração Latino-Americana, Brasil). E-mail: hernan.venegas@unila.edu.br

${ }^{3}$ Profesora e Investigadora de la Facultad de Psicología (Universidad de Salamanca, España). E-mail: crisje@usal.es
} 


\section{Ma`ê pyahu kuña ypykuérare / Nuevas miradas a las mujeres indígenas}

La participación en la política de mujeres indígenas es un tema aún poco diseminado y debatido en ambientes académicos de países como Argentina, Bolivia, Brasil y Paraguay. Los pueblos guaraníes de estos países representan una parte importante de lo que se denomina aquí como "Sur Amerindio": una metáfora convergente de los conceptos: "Sur" y "Amerindio". Por un lado el término "Sur" nos remite a realidades globales, subdesarrolladas y periféricas a los centros hegemónicos en el mundo contemporáneo. Ya el concepto "Amerindio (a)", en desuso desde el punto de vista académico, ha sido empleado para referirse a los pueblos bajos y altos de las Américas. No es este el relato epistémico que nos interesa, sino la dimensión que de ese Sur (periférico y subdesarrollado) Amerindio (subalterno, mestizo e indígena) es capaz de evocar. A partir de la década de 1990 en este Sur Amerindio, más guaraní y subalterno, la participación de mujeres indígenas en la política es un fenómeno de destaque. Por esos años dos eventos llaman nuestra atención: el "Enlace Continental de Mujeres Indígenas de las Américas" (ECMIA, 1993) y la "Red de Mujeres Indígenas sobre Biodiversidad" (RMIB, 1998). Sus principales demandas se concentraron en los derechos humanos básicos de sus pueblos - al agua potable, a la educación específica, diferenciada y plurilingüe y a la salud diferenciada. Otros dos reivindicaciones centrales son la restitución de territorios indígenas y el cuidado de la naturaleza. Unido a estos dos últimos, la inclusión y reconocimiento social de la mujer indígena han sido pautas vehementes de eventos realizados en Ecuador, México, Perú y Guatemala ${ }^{4}$.

Para mejor entender estas reivindicaciones se hace necesaria una mirada a estudios indígenas referentes a los períodos pre-colonial y colonial. Pensar el lugar de la mujer indígena en los siglos XV y XVI es un ejercicio interesante de análisis para una mejor comprensión de las dinámicas internas de los pueblos del Sur Amerindio. Por ejemplo, en culturas indígenas mesoamericanas (Olmeca, Maya, Azteca, Teotihuacana) la mujer indígena era valorada al mantener el equilibrio en la complementariedad, y en su rol reproductor para la transmisión del linaje (HERNÁNDEZ ASTETE, 2013). Según la feminista y política paraguaya, Lilian Soto, en tales culturas la representación de la mujermadre, implica el rol de ser las transmisoras de valores, conocimientos y costumbres del pueblo de generación en generación, por lo que la construcción de la imagen de la mujer-madre debía ser preservada (SOTO, 2014).

Lo doméstico y público, en el universo indígena estaban bien delimitados, en culturas como la azteca el cordón umbilical de la niña era enterrada en el hogar de la familia, esto a diferencia del varón cuyo

\footnotetext{
${ }^{4}$ El 1 er. Encuentro Continental del ECMIA, celebrado en Quito (Ecuador) en agosto de 1995, $1^{\text {a }}$. Cumbre de Mujeres Indígenas de las Américas (México, 2002), la 1ª Cumbre Continental de Mujeres Indígenas (Perú, 2009), el VI Encuentro Continental de Mujeres Indígenas de las Américas (México, 2011) y el VII Encuentro Continental de Mujeres Indígenas (Guatemala, 2015).
} 
cordón umbilical era enterrado en el campo de batalla (BÁRCENA DÍAZ, 2015). Es esta una clara imagen de los destinos, la mujer estaba destinada a lo doméstico y el hombre a lo público. Obviamente existen excepciones sobre los pequeños y escasos accesos al poder. Por ejemplo - la antropóloga mexicana Mercedes Oliveira, narra en sus estudios que hubo mujeres que ejercieron un papel de destaque en la vida política de la cultura maya (OLIVEIRA, 2003), elemento este en el que coinciden las investigadoras Isi V. Lara y Lily Lara (LARA y LARA, 2017), aunque con poca presencia en cargos políticos relevantes, sí con una legitimidad genealógica en la conformación de los linajes vinculados a las formas de gobierno en el mundo maya. De acuerdo con la historiadora y antropóloga argentina Florencia Roulet, la exclusión del mundo público estaba también determinado por el factor étnico, pues el mismo constituía "un elemento de segregación/jerarquización, en donde las guerras de conquista establecen las posiciones de servidumbre, teniéndose en cuenta para ello el sitio que se ocupaba previamente en la comunidad conquistada" (ROULET, 1993, p. 52).

Por su vez, de acuerdo con la antropóloga Rita Segato, el dualismo del género en el mundo indígena, es diferente. Según Segato, puede afirmarse que "la relación de género en este mundo configura un patriarcado de baja intensidad, si comparado con las relaciones patriarcales impuestas por la colonia y estabilizadas en la colonialidad moderna" (SEGATO, 2012, p. 123). Esta especialista trae su experiencia de pueblos andinos, amazónicos y chaqueños, donde no existe el monopolio de la política por el espacio público y sus actividades, como en el mundo colonial moderno. Al contrario, en los pueblos mencionados el espacio doméstico es dotado de politicidad, por ser de consulta obligatoria y porque en él se articula el grupo corporativo de las mujeres como frente político (SEGATO, 2012). Otra especialista que des-cubre la naturaleza de los espacios público y doméstico de pueblos indígenas es Mariana Gómez. Las investigaciones de esta antropóloga con las mujeres qom (tobas) en comunidades del Chaco argentino, señalan que "la marcada división entre espacio público y doméstico es un producto histórico de los procesos de colonización" y donde en "el pasado los tobas, eran cazadores, recolectores, pescadores con un sistema de sexogénero matrilocal", (GÓMEZ y SCIORTINO, 2018, p. 9).

En un otro universo, el de los pueblos guaraníes, de organización "matrilocal" - término utilizado en la antropología social al referirse a la matrilinealidad de la familia, la vida comunitaria gira en torno a la abuela sabia, ella es quien guía, orienta y decide lo que respecta al hogar y a la familia. Hacia afuera de la comunidad el representante legal es el hombre y en su interior el liderazgo siempre fue compartido en la pareja. Nuestro trabajo de campo junto a los Guaraní del este de Paraguay, del sur de Brasil y del nordeste de Argentina nos permiten afirmar que el hombre sólo - trátese de líderes antiguos que aún perduran - no tiene la autoridad plena. Él debe consultar necesariamente a su "takuajary" (esposa), quien es la dueña del fuego en el hogar y del elemento ritual femenino (takua). Además, tenemos experiencias de otros pueblos presentes en el Paraguay como los Nivaclé y los Ayoreos, que posibilitan otra lectura, 
insubordinada, ante la sociedad que se empeña en no reconocer su herencia indígena y aún menos adentrarse en sus misterios y encantos. Uno de ellos es la "matrilocalidad", en lo que el aporte de las mujeres va como organizadoras de la vida socioeconómica y religiosa de toda la comunidad.

Los argumentos anteriores están además relacionados con las ideas de Bartolomé Meliá, especialista en temas guaraníes, al afirmar que:

La mujer en ninguna sociedad es solamente mujer, hasta cuando cumple la función biológica de ser madre, lo es ante todo como un ser social (...) como un intermediario de una acción divina que a través de ella crea un nuevo cuerpo para una nueva alma", (MELIÁ, 1991, p. 79).

Otra especialista en el tema, la antropóloga alemana radicada en Paraguay, Beate Lenher, señala que en la cultura guaraní existe casi un paralelismo total respecto a las actividades masculinas y femeninas (LENHER, 2005). Tal paralelismo se caracteriza por la diferenciación que hacen en la cultura de lo que debe hacer una mujer y lo que el hombre a su vez, y estos roles asignados aún se llevan a cabo como tal en comunidades rurales, no así en las urbanizadas. Como ejemplo traemos los quehaceres de la casa, de los cultivos cerca del hogar y de la crianza de los hijos que se encargan las mujeres y el hombre de traer el sustento para la familia, sean productos del cultivo más extenso y la renta de estos, como también de la caza o "changas", es decir, trabajos esporádicos realizados fuera de la comunidad. No obstante a los argumentos señalados, la incomprensión del papel de la mujer en la cultura guaraní se debe en gran medida al imaginario occidental, con más vehemencia en sus representaciones a partir de la conquista y colonización.

Precisamente, un trabajo que permite entender esa relación con el otro - "salvaje, no civilizado" - es de la autoría del antropólogo Roger Bartra y publicado en 2011. Este destacado intelectual mexicano demuestra que "los hombres salvajes son una invención europea que obedece esencialmente a la naturaleza de la cultura occidental" (BARTRA, 2011 , p. 15). También argumenta que la falta de una cabal comprensión de la historia del hombre salvaje europeo - un mito enraizado en la propia existencia del Occidente - puede oscurecer considerablemente la visión de la conciencia colonialista y de las imágenes occidentales de ese "Nuevo Mundo". Esta imagen distorsionada y la poca profundidad del conocimiento del universo indígena obstaculizan una aproximación más fidedigna al universo social de los indígenas. Además, una vez que los pueblos autóctonos son presentados como salvajes se evita reconocer la condición cultural del otro.

En esta línea de reflexión, reivindicatoria y crítica, se coloca el antropólogo argentino Guillermo Wilde. Wilde argumenta que los estudios sobre la expansión europea y el contacto colonial en América y el mundo presentan dos perspectivas de análisis. Por un lado, "las historias de las poblaciones indígenas post-contacto constituyen versiones locales de la difusión capitalista o, por el contrario, expresan modalidades singulares 
y autónomas de construcción de la alteridad" (WILDE, 2009, p. 35). Es un ejercicio de interpretación de desenmarañar los falsos mitos y lecturas tradicionales de la historiografía sobre el papel de los indígenas en América. No pocos especialistas han investigado el papel de la mujer guaraní en su cultura. Branislava Susnik ${ }^{5}$ y Bartolomeu Meliá argumentan, que la imagen creada por los Guaraníes, quedó totalmente distorsionada con la llegada de los colonizadores (MELIÁ, 1991).

Susnik afirma que "las mujeres eran consideradas piezas para el trabajo: una pieza que puede ser comprada, vendida, trocada, jugada junto a una mesa de naipes" (SUSNIK, 1965, p.12). Por su parte, Florencia Roulet, comenta que las mujeres en tal época han pasado a ser "compañeras, amantes, criadas, cargadoras, madres, agricultoras y cocineras, esclavas transformadas en mercancía humana trocada por armas o caballos" (ROULET, 1993, p. 277). Y la historiadora brasileña, Cristina Scheibe Wolff, señala que "as mulheres, desde a infância, eram aprisionadas, estupradas, vendidas ou trocadas por mercadoria, para serviços sexual, doméstico e produtivo" (WOLFF, 1999, p.32). Los ejemplos anteriores permiten afirmar que el colonialismo ibérico reservó un lugar, subordinado y desvirtuado, lejos del equilibrio y complementariedad espiritual que caracterizaba a las mujeres indígenas guaraníes. Los estudios citados contribuyen para relativizar categorías herméticas y esquemas binarios de interpretación sobre el universo indígena habituales en las miradas occidentales sobre el Sur Ameríndio.

Actualmente existen respuestas de las mujeres guaraníes ante tal situación en el plano regional y local que reivindican el lugar de la mujer en la cultura y sociedad. Un ejemplo de organización y empoderamiento lo es el "Colectivo de Mujeres Indígenas del Chaco Americano"6 - que se inicia en 2003, con el objeto de visibilizar la necesidad de contar con espacios y tiempos que permitieran analizar, reflexionar, intercambiar y planificar acciones con perspectiva de género. Tal colectivo aglutina organizaciones de mujeres indígenas de la "Nación Continental Guaraní" (Figura 1) - concepto empleado por primera vez en Asunción, 2010, en ocasión del "3er. Encuentro Continental de la Nación Guaraní". Este es un concepto geográfico-cultural acuñado por los propios guaraníes que hace referencia a los espacios ocupados ancestralmente y que siguen ocupando en Argentina, Bolivia, Brasil y Paraguay.

\footnotetext{
${ }^{5}$ Branislava Susnik (1920- 1996) es una etnógrafa y lingüista eslovena radicada en Paraguay desde 1951. Sus estudios identificaron cinco familias lingüísticas de los diecinueve pueblos indígenas presentes en Paraguay. Trabajó en Paraguay durante 45 silenciosos años, para plasmar la etnohistoria de los indígenas guaraníes y chaqueños, dejando como legado más de 70 publicaciones y contribuyendo de forma significativa en la creación del Museo Etnológico "Andrés Barbero", de Asunción, Paraguay. Cf. https://www.museobarbero.org.py/

${ }^{6}$ Disponible en: https://www.colectivomujeresdelchaco.org y https://h5p.org/h5p/embed/107098
} 
Figura 1: Guaraní Continental (Argentina, Bolivia, Brasil y Paraguay)

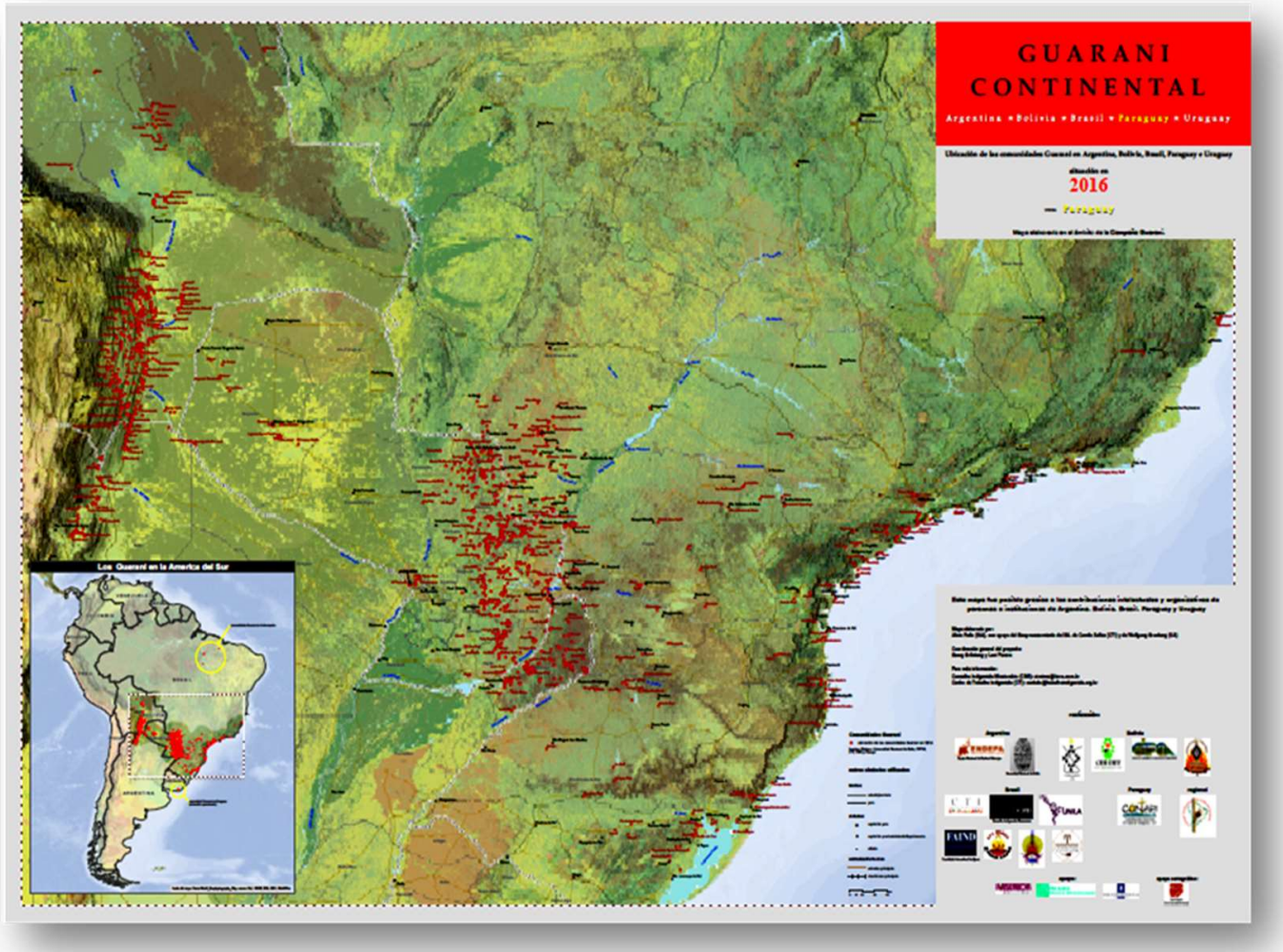

Fuente: Mapa Guaraní Continental (2016)

Además, el "Colectivo Chaco Americano" - integrada exclusivamente por mujeres, es parte del Instituto Agroecológico Latinoamericano Guaraní (IALA) ${ }^{7}$ que funciona en países sudamericanos. El IALA tiene como objetivo brindar educación gratuita a nivel de estudios de pregrados y grados a sus integrantes campesinos e indígenas en países como Brasil (ELAA, 2005 e IALA Amazónico, 2009), Venezuela (IALA-Paulo Freire, 2006), Paraguay (IALA, 2008 y CONAMURI, 1999) y en Chile (ANAMURI, 2009, IALA Mujeres 2014). Estas instituciones están diseñadas para enseñar bajo una concepción pedagógica y filosófica de educación liberadora - grosso modo, una pedagogía que se contrapone a una pedagogía "bancaria" en la que se limita la creación de los propios conocimientos $^{8}$. Tales instituciones potencian cursos innovadores de agroecología en línea del desarrollo sostenible, soberanía alimentaria y la emancipación de las mujeres, valorando sus saberes ancestrales y del pueblo. Tienen por principio incorporar la cosmovisión y el respeto hacia los pueblos indígenas y contribuir al desarrollo integral de las mujeres rurales e indígenas, considerando los aspectos laborales, económicos, sociales y culturales, sustentados en una ideología que apunte a la

\footnotetext{
${ }^{7}$ Disponible en: https://ialaguarani.wordpress.com/acerca-de/

${ }^{8}$ Entiéndase una pedagogía propuesta por el pedagogo brasileño Paulo Freire (1921-1997) cuyo método trae consigo el desarrollo del conocimiento crítico y potencia la reflexión del individuo. Dos de sus obras pioneras y referenciales son: "La educación como práctica de la libertad", de 1969 y "Pedagogía del Oprimido", de 1970.
} 
construcción de relaciones de igualdad en términos de género, clase y pueblos originarios, en un ambiente equilibrado entre las personas y la naturaleza.

La experiencia demuestra que si bien los pueblos indígenas del Cono Sur viven distintas realidades, tienen un problema en común. Mujeres y las organizaciones del campo deben hacer frente a la situación política del país, que ha modificado sus prácticas de producción de alimentos. El agronegocio ha degradado prácticas agroecológicasancestrales $^{9}$ y ha potenciado los monocultivos que obliga el uso de agrotóxicos, extracción de recursos forestales y mineras, que trae el desalojo de los campos aumentado los problemas con relación al acceso a la tierra y al agua. Al respecto el reconocido médico paraguayo y activista de derechos humanos, Joel Holden Filártiga Ferreira, pionero en estudios sobre efectos de agrotóxicos en la salud humana en Paraguay, argumenta que este y los países vecinos se encuentran bajo la dictadura de la oligarquía sojera, vacuna y multinacional (FILÁRTIGA y AGUERO, 2004). Obviamente, de carácter predatorio para la región y, en especial, para las actividades agrícolas y la propia existencia de las comunidades indígenas de estos países del Cono Sur de América.

A pesar de los potenciales y reales cambios que la educación ${ }^{10}$ es capaz de propiciar, la actuación política constituye un espacio para aplicación de políticas públicas específicas para las poblaciones indígenas. Sin embargo, no es suficiente que las constituciones de países como Argentina, Bolivia, Brasil y Paraguay hayan reconocido en sus cartas magnas $^{11}$ la preexistencia de los pueblos indígenas antes de la conformación de los estados nacionales, y que a estos se les reconozca su organización social, económica y religiosa propia. Una reivindicación, ideal de vida y propuesta de alteridad indígena es el "buen vivir". Este concepto constituye un ideal de vida de los pueblos indígenas de

\footnotetext{
${ }^{9}$ Ejemplos de esas prácticas aún vigentes entre los guaraní son: la quema controlada y la siembra sobre cobertura vegetal, de forma asociada y escalonada. En todas las actividades agrícolas se respetan el ciclo lunar por su significado cultural - augurio de una buena y sana cosecha, motivo por el que se realizan los rituales de bendición de semillas de los primeros frutos, donde se comparten las semillas por el sentido de reciprocidad - el "jopói”.

${ }^{10}$ En los últimos años hemos identificado una producción científica relevante en temas de educación y pueblos guaraníes. En Argentina: un interesante aporte sobre la educación de los Mbya y Ava Chiripa es de Yamila Irupé Núñez bajo el título: Educación superior e interculturalidad en Misiones-Argentina, publicado en Textos\&Debates, Boa Vista, n.21, pp. 59-74, jan./jun. 2012 y otro de Noeli Enriz con el título: Un sueño blanco: reflexiones sobre la educación mbyá-guaraní en Argentina, publicado en Amazônica 2 (1), 28-44, 2010. En Bolivia contamos con el análisis de Marcia Mandepora Chundary, con el título: Estrategias de interculturalización de la gestión educativa de la UNIBOL “Apiaguaiki tûpa" que trata de la experiencia en la Universidad Guaraní desde 2008, editada y publicada por Mónica Navarro en su obra Entre la práctica y la teoría. Aportes para la construcción de una gestión educativa intra e intercultural en Bolivia, Cochabamba, 2016, pp 204-224. En Brasil contamos con la investigación de Catarina Costa Fernandes en su obra: Os Guarani Mbya a manutenção de sua cultura a través do currículo como política social e cultural (2006); de Marilda Moraes Garcia Bruno y Renato Suttana bajo el título: Educação, diversidade e fronteiras da in/exclusão, publicado en Dourados, MS: Editora da UFGD, 2012 (trata sobre los guaraní Kaiowa). En Paraguay contamos con la investigación de Bartomeu Melia con el título: Educación indígena y alfabetización, publicado en Asunción, 2009.

${ }^{11}$ Las referencias a la preexistencia de los pueblos originarios en las constituciones están presentes en los siguientes artículos: Brasil - artículo 231, 1988, Paraguay - artículo 62, 1992, Argentina - artículo 75, inciso 17, 1994 y Bolivia - artículo 30, 2009.
} 
Latinoamérica reivindicada por ellos en resistencia a la asimilación cultural y es una propuesta de alteridad indígena. El buen vivir es una alusión hecha desde el siglo XVII en el "Tesoro de la Lengua Guaraní" (1639), escrito por Antonio Ruiz de Montoya (1585-1652). Para este sacerdote jesuíta el "buen vivir" es caracterizado como un modo de ser, un buen estado de vida: venturoso, alegre, contento y satisfecho, feliz y placentero, apacible y tranquilo (apud MELIÁ, 2016, p. 234). En el universo multicultural andino es sinónimo del "sumak kawsay" y, para la experiencia de vida de los guaraníes, es entendido como "teko porâ". Este último se traduce en un territorio conformado por bosques, arroyos y campo de cultivo, en calidad de vida armónica con la naturaleza.

Sin embargo, las consecuencias de prácticas no sostenibles del agro-negocio, la ganadería y el extractivismo trajeron como resultado la expulsión y/o desplazamiento de comunidades guaraníes de sus territorios originarios. Tal cuadro nefasto ha obligado a las comunidades a buscar su "buen vivir" en circunstancias ajenas a su derecho de vivir según su autodeterminación, sea en el campo, en aislamientos voluntarios o en la ciudad. En fin, el buen vivir, como acertadamente apunta Aníbal Quijano, es la formulación más antigua de la resistencia indígena frente a la "colonialidad del poder"12 (QUIJANO, 2000, p. 207) y la reafirmación de la existencia de un modo de vida diferente al occidental. Contra tal realidad se han levantado las voces de las mujeres indígenas en la arena política desde las últimas dos décadas.

\section{Kuña ypykuéra ojepytaso polítikape / Participación política de mujeres indígenas}

La incursión política de las mujeres indígenas - en lengua guaraní, "Kuña ypykuéra ojepytaso ${ }^{13}$ politíkape"- en Argentina, Bolivia, Brasil y Paraguay, es de nuestro interés en este apartado. Iniciamos planteando el género, ya que nuestro estudio refiere a las mujeres. Este último desde el punto de vista conceptual fue propuesto en 1955 por el investigador psicólogo, especializado en sexología, John Money. Específicamente el término por él utilizado fue "papel de género" para describir el conjunto de conductas atribuidas tanto a hombres como a mujeres, (FAÚNDEZ y WEINSTEIN, 2011 , p. 17). Según señalan Money y Trucker la adquisición de la identidad de género se da a través de un mecanismo similar a la del lenguaje y que necesita de un estímulo social, ya que: "al nacer, el circuito impreso ya estaba, pero la programación no estaba establecida, como en el caso del lenguaje. Su identidad de género no podía diferenciarse ni

\footnotetext{
${ }^{12}$ Aníbal Quijano - sociólogo y pensador humanista peruano, se refiere con este concepto a las configuraciones culturales e intelectuales resultantes de la dominación colonial en América. Cf. QUIJANO, Aníbal. "Colonialidad del poder, eurocentrismo y América Latina”. En: La colonialidad del saber: eurocentrismo y ciencias sociales. Perspectivas Latinoamericanas. CLACSO, Consejo Latinoamericano de Ciencias Sociales, Buenos Aires, Argentina. Julio de 2000. pp 201- 246.

${ }^{13}$ Literalmente, en lengua guaraní "ojepytaso" esta palabra significa "soltar los pies de" traducida por esfuerzo, como lo señala Lino Trinidad, respetado investigador paraguayo de la lengua guaraní, en su obra el diccionario ÑE'ÊNDY RAITY. Ñe'êryru, Guaraní - Castellano / Castellano - Guaraní, publicado en Asunción de 2008.
} 
llegar a ser masculina o femenina sin estímulo social" (MONEY y TRUCKER, 1978, p. 88). Sin embargo, el género como objeto de estudio científico, se relaciona al campo de la psicología médica con el psicoanalista y psiquiatra norteamericano Robert Stoller, en 1964. Este especialista estadounidense estableció claramente la diferencia conceptual entre sexo y género, al utilizar el concepto de "identidad de género" aplicado a los estudios sobre trastornos de la identidad sexual (HERNÁNDEZ, 2006).

De acuerdo a la antropóloga estadounidense Gayle Rubín, el género "es una división de los sexos socialmente impuesta, un producto de las relaciones sociales de sexualidad" (RUBIN, 1986, p. 114). Para la antropóloga mexicana Marta Lamas, los sexos son construcciones culturales simbólicas más allá de los datos biológicos, (LAMAS, 2000). A su vez, el "género" es entendido como un elemento constitutivo de las relaciones sociales basadas en las diferencias que distinguen los sexos. O sea, una forma primaria de relaciones significantes de poder (TARRÉS, 2013). Existe un denominador común en estas definiciones sobre el género y es la dimensión social de este concepto es portador, más allá de pre condicionamientos biológicos. En esta dirección se destaca la antropología feminista por las voces de: Jane Collier, Michelle Rosaldo, Sherry B. Ortner y Louise Lamphere. Sus estudios dieron comienzo a líneas de indagación sobre los vínculos entre mujeres y política en pueblos indígenas (GÓMEZ y SCIORTINO, 2018, p. 15).

En la década de los setenta, sobretodo, a partir de la publicación de Women, Culture and Society compilado por Rosaldo y Lamphere (1974) y Toward an Anthropology of Woman, compilado por Rayna Reiter (1975), fueron revisitadas las miradas académicas en relación al género que imperaba en la Antropología. En este sentido, los trabajos de Rosaldo pueden ser considerados un punto de partida hacia la construcción de una perspectiva de género crítica hacia los modelos interpretativos que definen a las mujeres como "dominadas" e imposibilitadas de enfrentar el poder masculino. Rosaldo sitúa en la división público-privado los fundamentos de la subordinación universal de las mujeres (GÓMEZ y SCIORTINO, 2018, p. 16). Uno de los aportes, tal vez más destacados de la Rosaldo, se refiere a la influencia de la mujer - y de manera informal en relación al poder. Así argumenta que "las mujeres tienen una influencia sistemática sobre las decisiones que son tomadas en sus comunidades, aunque no tengan derecho ni obligación de tomar decisiones" (ROSALDO, 1979, p. 157).

Por su parte, Jane Collier en su emblemático artículo sobre mujeres y política "Women in Politics" presenta aspectos de la "política doméstica" en el "espacio doméstico". En este artículo, la autora trata a las mujeres como agentes activos en sus comunidades con diversos intereses si se comparan a los hombres. Igualmente reconoce la existencia de una "politización del espacio doméstico", donde ellas ejercen el poder a su modo y medida imponiendo autoridad femeninos (COLLIER, 1974). En la misma línea, "muchas culturas, particularmente las indígenas con estructura tribales, la separación doméstico y público carece de sentido porque la producción del grupo familiar es simultáneamente pública, económica, y política" (LAMPHERE, 1993, p. 70). Entre lo doméstico y lo 
público, no necesariamente existe una barrera inaccesible, sino aproximaciones de los límites entre espacios sociales. En similar línea revisionista Camila Gómez, especialista brasileña, sostiene que los estudios de género contemporáneos ubicados más allá del discurso moderno occidental reconocen al ausencia de una estructura jerárquica en los pueblos indígenas. Las culturas de pueblos indígenas revela una

maior transitoriedade das posições de gênero, uma relativa igualdade, uma divisão de tarefas que não se assemelha ao que se convencionou chamar divisão sexual do trabalho (...) é o exemplo do fazer gênero de povos originários da América Latina, em que concepções múltiplas ou duais são substituídas pela imposição binária colonial (GOMES de MAGALHÃES, 2018, p 70).

Un ejercicio interesante de reflexiones en este artículo es la comprensión del género en países como Paraguay, Bolivia, Argentina y Brasil. Y, más específicamente, el estudio de esa dimensión social del concepto de género en relación a la participación política de mujeres indígenas en estos países. Ese ejercicio trae consigo un estudio crítico de las relaciones de poder a partir de prácticas patriarcales en las sociedades latinoamericanas. Al mismo tiempo aporta nuevas formas de interrogar la realidad al visibilizar el liderazgo indígena femenino en comunidades indígenas.

En Paraguay los estudios teóricos referente al género están en una etapa inicial. Sólo algunas instituciones privadas como: "Amnistía Internacional en Paraguay", "Coordinadora por los Derechos Humanos en Paraguay" (CODEHUPY) y "Centro de Documentación y Estudios" (CDE), que actualmente investigan y publican al respecto, pues aún la política estatal se muestra insuficiente. No obstante, cuenta con un Ministerio de la Mujer ${ }^{14}$, creado por Ley $\mathrm{N}^{0} 4.675 / 2012$, un organismo público cuyo objetivo principal es propugnar el protagonismo y la participación de la mujer en el ámbito de la vida política, cultural, familiar, laboral y social. Este objetivo se sitúa en el marco de la "Convención de la Eliminación de toda forma de discriminación de la Mujer (CEDAW)", ratificada por la Ley $N^{0} 1.215 / 1986$. Sin embargo, no se constata su apuesta real de promoción de las mujeres paraguayas y menos aún de las mujeres indígenas. La sociedad paraguaya se caracteriza por un conservadurismo respecto al debate sobre género: esto permite entender la insuficiente participación política de la mujer paraguaya siendo mayor el desafío para las mujeres indígenas de los pueblos indígenas del Paraguay ${ }^{15}$.

Una conquista importante en la arena política paraguaya de los años sesenta, aunque tardía, fue el derecho al sufragio femenino (1961). Paraguay fue el último país sudamericano en otorgar este derecho: una jurisprudencia en tal sentido se abre desde entonces. La Constitución de

\footnotetext{
${ }^{14}$ Disponible en: http://www.mujer.gov.py Acceso en: 10 febrero 2018

${ }^{15}$ Según datos de la Dirección General de Estadísticas, Encuestas y Censos (DGEEC) existen actualmente en Paraguay 19 pueblos indígenas, que representa el 1,8\% de población indígena ante la población total del país. Cf (DGEEC, 2014).
} 
Paraguay 1967, en su artículo 51, consagra la igualdad de derechos civiles y políticos del hombre y de la mujer, y la Constitución de 1992 en su Artículo 48 refuerza y garantiza la igualdad de derechos entre hombres y mujeres, y promueve la implementación de acciones para lograr la vigencia de la igualdad. Como se puede apreciar, al menos, constitucionalmente está previsto tal aspecto. Sin embargo, el derecho a gobernar o de ocupar puestos en el estado comienza a ser objeto de reclamos sólo en la década de 1990. Precisamente, en 1996, fue aprobada la Ley Electoral 834/96 que establece la cuota mínima del 20\% de mujeres en las listas electorales (Art. 32, Inciso R), según afirman Soto (2015) y ONU Mujeres Paraguay (2015). De acuerdo con la politóloga paraguaya Sarah Cerna, especialista en la temática, "como resultado de las elecciones de 2013, el índice de participación política de las mujeres en el Parlamento del Paraguay alcanzó el 17\%"16 , y en las elecciones generales de abril de 2018 este porcentaje cayó para el 15\%. O sea, no se ha llegado al límite estipulado por ley y, aún más, los resultados alcanzados en relación a la participación femenina en la política paraguaya han disminuido.

Más recientemente, en marzo de 2016, la Cámara de Senadores del Paraguay incorporó a su agenda un Proyecto de Ley de "Paridad Democrática" impulsado por activistas en Derechos Humanos, con el propósito de lograr la igualdad política entre hombres y mujeres. Ese proyecto fue ratificado en marzo de 2018 por Cámara de Senadores sin embargo fue negado por la Cámara de Diputados en octubre de 2018 . Así la política paraguaya, seguirá sin cambios en la participación de mujeres. En el caso de los indígenas del Paraguay, el artículo 62 de la Constitución Nacional de 1992 reconoce la preexistencia de los pueblos indígenas antes de la conformación del Estado paraguayo y, teóricamente, otorga los derechos plenos de autodeterminación. Esto no se corresponde con la realidad de los grupos indígenas existentes en territorio nacional paraguayo y, menos aún, se aplica a las mujeres indígenas y la política del Paraguay. Sobre ellas también inciden factores externos que atentan contra el protagonismo político que otrora era una realidad, y que traen consigo cambio de modalidades de las actividades de subsistencia de los indígenas.

Actualmente los hombres indígenas salen de sus hogares y fuera de la comunidad a realizar trabajos esporádicos y las mujeres permanecen en la casa al cuidado de los hijos y del cultivo de productos de autoconsumo y ser la cabeza visible ante la sociedad. Y muchas de ellas también salen a las ciudades a realizar trabajos domésticos. En este contexto, la pérdida de las culturas tradicionales, sin la contrapartida de procesos transculturales adaptativos, genera un quiebre del lugar de la mujer, que gozaba de mecanismos simbólicos, rituales y, aún míticos, que aseguraban cierta dignidad de su situación social y su participación política (SOTO, 2014). Es a partir de esta pérdida de su lugar en el interior de la familia, de la comunidad y su necesaria incursión en la sociedad

\footnotetext{
${ }^{16}$ En línea: ¿Cómo las paraguayas hacen carrera política? http://www.paraguay.com/nacionales/como-lasparaguayas-hacen-carrera-politica-118720. Acceso: 16 de enero de 2018.
} 
fuera de su comunidad que la mujer indígena sufre de una triple discriminación: étnica, de clase y de género. La sociedad paraguaya no ha sabido aún valorar suficientemente la presencia de la mujer indígena, su aporte cultural como pueblo y, menos aún, sus derechos legales como indígenas. Obviamente, esto explica el carácter desproporcionado entre la participación en la vida pública de la sociedad paraguaya y el rol de la mujer en el seno de sus comunidades indígenas. Tal visibilidad ha sido reconocida por las visitas de campo realizadas en la región oriental de Alto Paraná y Canindeyú de Paraguay y en el estado de Paraná, Brasil, junto a comunidades guaraníes.

Por otra parte, no pocos especialistas coinciden sobre el protagonismo y visibilidad de las mujeres indígenas en sus comunidades. Bartomeu Meliá llama la atención la frecuencia con que las mujeres indígenas han constituido sus liderazgos en el interior de la cultura Guaraní en Paraguay, antes confiado a los hombres ser el representante legal visible de la comunidad (MELIA, 2014). Raquel Peralta ${ }^{17}$, antropóloga paraguaya, argumenta que el liderazgo femenino Guaraní siempre ha existido. Sin embargo, nunca fue tan visible por su particularidad y diferencia del liderazgo femenino no indígena (PERALTA, 2018). Peralta también recuerda un Ilamado de una lideresa Guaraní: "ha llegado la hora en que debemos salir de nuestras fogatas ("rataypy") y acompañar a nuestros hijos o esposos a realizar nuestros legítimos reclamos de los derechos negados, pues ya no es suficiente enviarles a ellos solos" (PERALTA, 2018). Varias organizaciones indígenas han llamado para sí las responsabilidad aludida. Ejemplo de esas organizaciones son: Kuña Guaraní Aty (“Asamblea de Mujeres Guaraní”), fundada en 2012 y Mujeres Indígenas del Paraguay (MIPY, 2014). Mujeres indígenas guaraníes y otros pueblos son parte de la Organización de Mujeres Campesinas e Indígenas (CONAMURI, 1999). Estos son espacios de ejercicio público del liderazgo y que impulsa a la acción política de la sociedad paraguaya. Vale subrayar que la política no es un espacio desconocido para las mujeres indígenas en sus comunidades, sí un espacio nuevo en la esfera de la sociedad paraguaya.

El liderazgo indígena ${ }^{18}$ de la mujer Guaraní es ejercido junto a "mena" (vocablo del guaraní paraguayo para referirse al marido) quien necesita del apoyo femenino al ser propuesto y electo en su comunidad para asumir la responsabilidad comunitaria. Por ejemplo, dos líderes indígenas guaraníes: Dorotea García (Figura 2) - cuyo marido es líder en la comunidad Arroyo Mokôi y presidente de la "Asociación Zona Alta de Canindeyú". Dorotea García, de 88 años, es una abuela sabia - "jarýí, en lengua guaraní y así es Ilamada en su comunidad. Delia Martínez, cuyo marido es vice cacique en la comunidad Ara Pyahu (ambas comunidades

\footnotetext{
${ }^{17}$ Peralta, Raquel (enero, 2018). Entrevista con la antropóloga paraguaya con vasta trayectoria entre los indígenas guaraníes, otros pueblos indígenas de Latinoamérica (Argentina, Bolivia, Brasil, Ecuador) y África (Ghana, Etiopía y Sudán del Sur).

${ }^{18}$ En la cultura guaraní, el liderazgo indígena es heredado y compartido en la pareja, o bien en la actualidad, puede ser una construcción colectiva. Esto en miras a inclusión a la sociedad, donde diseñan una infraestructura organizativa que va desde lo local, nacional y hasta lo internacional. Es para luchar porque sean reconocidos como sujetos jurídicos de derechos individuales y colectivos.
} 
de Canindeyú - Paraguay), afirman que maridos de mujeres guaraníes han consultado con ellas para asumir el liderazgo de sus comunidades (GARCÍA, 2018 y MARTÍNEZ, 2018) ${ }^{19}$.

Ellas se refieren a una práctica política socio-ancestral Guaraní, o sea, a la consulta masculina de los líderes guaraníes a sus esposas. Hasta las primeras décadas del siglo XX, la alianza sociopolítica en el territorio, "se manifestaba en un liderazgo unificado donde el sabio anciano, junto a su esposa ("takuajary") - dueño del takua, elemento ritual femenino-, ejercían el liderazgo religioso y político al mismo tiempo por derecho consuetudinario" (CÁCERES et al. 2017, p. 90). Otro aspecto importante es que el liderazgo era heredado tanto por línea materna o paterna, con el requisito fundamental de contar con la habilidad de la palabra, según nuestras experiencias etnográficas de trabajo en campo ${ }^{20}$. Esta práctica se ha modificado en las últimas dos décadas, más específicamente constatado en comunidades guaraníes del departamento de Canindeyú región oriental de Paraguay.

Figura 2: “Jarýi”” Dorotea García, Canindeyú - Paraguay.

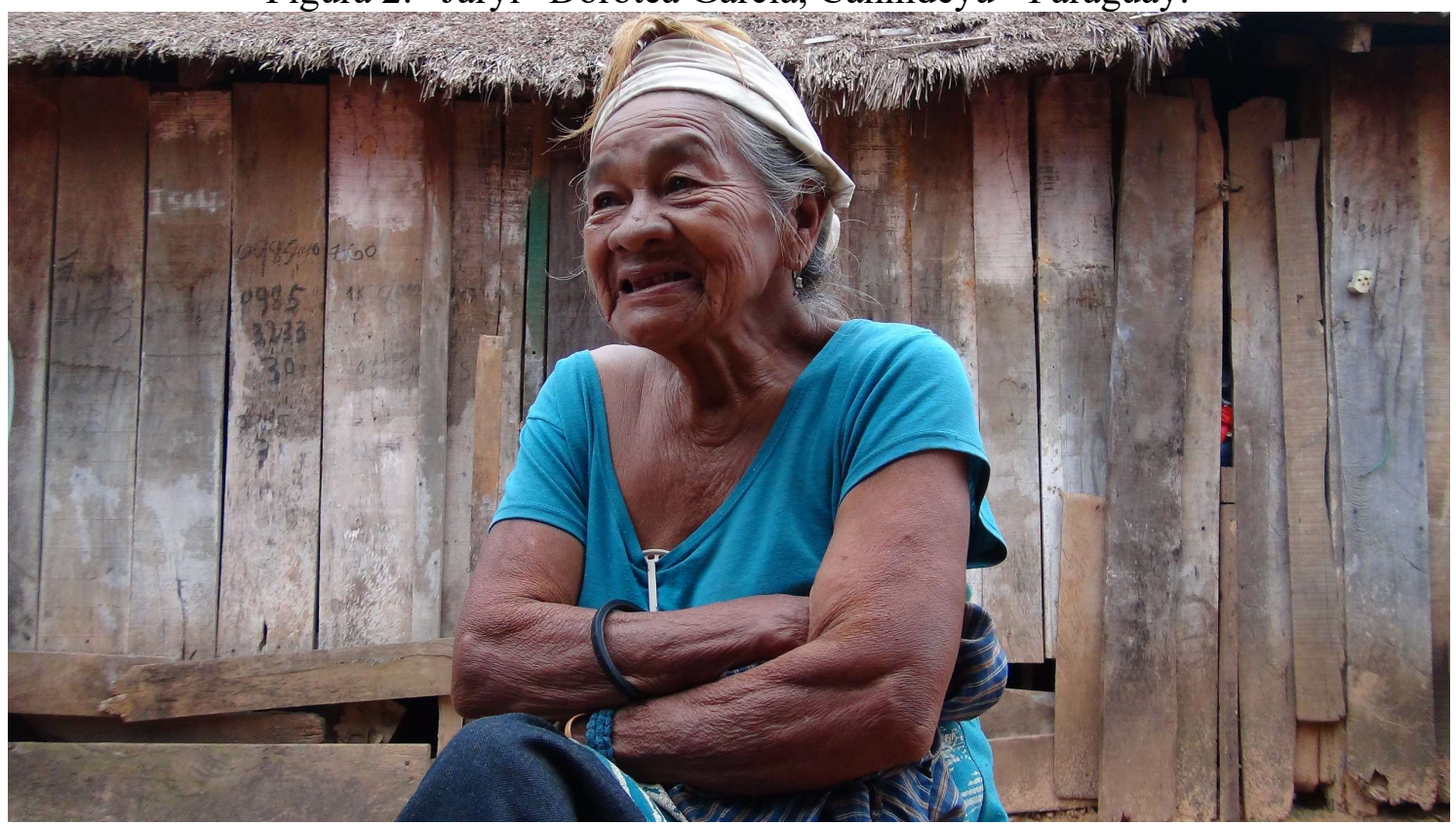

Fuente: Fotografía de Claudia Cáceres - julio de 2017.

Existe un factor legal que ha roto con la práctica sana de organización sociopolítica ancestral, en la que el rol de liderazgo era compartido: la Ley 904/1981 Estatuto de la Comunidades Indígenas. Esta Ley solicita en su Artículo 9, inciso "C", el "Nombre de los líderes y justificación de su autoridad para todas las gestiones a realizar" y en su Artículo 12 expresa: "Los líderes ejercerán la representación legal de su

\footnotetext{
${ }^{19}$ Informaciones obtenidas en trabajo de campo con mujeres guaraníes.

${ }^{20}$ Este trabajo etnográfico fue realizado en comunidades Ava-Guaraní de la región oriental, departamento Canindeyu de Paraguay, entre octubre de 2016 a junio de 2018 y su resultado fue recogido en una serie de entrevistas grabadas a líderes indígenas: Julio Martinez, Ramón López, Delia Martinez, Lorenza Benítez, Sixta Martinez, Cristóbal Martínez, Ignacia Velásquez, Miguela Duarte. Además. la autora principal de este trabajo - Claudia Cáceres, cuenta con una acervo personal de 102 entrevistas grabadas en comunidades de Brasil y Paraguay, en territorios Ava-Guaraníes.
} 
comunidad (...)" (Ley, No. 904/1981). A pesar de la promulgación de esta Ley las comunidades indígenas tardaron dos décadas en implementarla, y sólo a inicios del 2000 se vieron obligados a crear la figura del líder político, recayendo la elección de liderazgo en un 95\% en los hombres para representar a su cultura ante la sociedad. Puede datarse 1993 como punto de partida de la participación política de las mujeres indígenas en la vida política paraguaya.

En los últimos veinticinco años han ganado ocho concejalías en su mayoría en la región del Chaco - región donde se concentra un $48 \%$ de la población indígena (PUEBLOS INDÍGENAS EN EL PARAGUAY, 2014, p. 54). En 1993, Faustina Alvarenga, de origen Guaraní Occidental, había accedido a una concejalía departamental en Central y, en 2001, Susana Pintos, Guaraní Occidental, fue electa concejal, que por primera vez era ocupado por una mujer indígena ese espacio de poder político en la Municipalidad de Mariscal Estigarribia (Boquerón-Chaco). A partir de las elecciones de 2008, en un gobierno de cambio, tras la hegemonía por 70 años del Partido Colorado ${ }^{21}$, una mujer indígena ocupó también por primera vez la titularidad del ente público responsable de las políticas para los pueblos autóctonos: el Instituto Paraguayo del Indígena (INDI). Su nombre es Margarita Mbywangi, Aché Guaraní, quien ejerció el cargo por cuatro meses en 2008, quien también había sido candidata al Senado por el Partido Tekojoja ("modo de vivir en justicia/igualdad"), cargo al cual no logró acceder en las elecciones generales del 2008. Otro ejemplo de las luchas políticas de las mujeres indígenas en el Paraguay lo representa Daniela Benítez, del pueblo Nivaclé, afiliada al Partido Kuña Pyrenda ${ }^{22}$ (literalmente, "lugar donde ponen los pies la mujer o plataforma de mujeres").

Kuña Pyrenda es el primer partido político socialista, feminista y ecologista del Paraguay y tuvo a Daniela Benítez como candidata a senadora en las elecciones generales de abril de 2018 , puesto este al que no logró acceder. Por otra parte y en agosto de 2018 , Agustina Alvarenga - especialista Guaraní en derechos humanos indígenas, fue nombrada asesora de políticas públicas de la titular Ana María Allén Dávalos del Instituto Paraguayo del Indígena (INDI). Benítez y Alvarenga, junto a otras mujeres indígenas, han participado en el 2008, de la elaboración del documento denominado "Agenda para la incidencia, Mujeres indígenas". En esta agenda reivindicatoria se plantean diecinueve demandas relacionadas con el derecho a la salud, al ambiente, a la educación, a la seguridad, a la no violencia, a la tierra y al territorio, para todo el país (SOTO, 2014).

La solución al problema de la inclusión de las mujeres en la política va más allá de promover leyes e implementar mecanismos para

\footnotetext{
${ }^{21}$ El Partido Colorado (Asociación Nacional Republicana, ANR) fue fundado en 1887, por el Gral. Bernardino Caballero (1839-1912) como un partido político nacionalista tras la Guerra de la Triple Alianza (1864-1870). Desde su fundación hasta inicios del siglo XXI el Partido Colorado ha gobernado el país de forma intermitente, durante la dictadura Stroessner (1954-1989) hasta 2008 y nuevamente desde 2013 hasta la actualidad.

${ }^{22}$ El Partido Kuña Pyrenda, fue fundado el 9 de noviembre de 2017, tras una reconocida trayectoria como Movimiento desde 2011. Recuperado de: http://www.kunapyrenda.org/
} 
cumplirlas. Para llegar plenamente este fin se hace necesario un cambio en las estructuras partidarias que integre a la mujer como actor político capaz de desempeñar funciones correspondientes. Con los ejemplos anteriores puede constatarse cómo las mujeres indígenas del Paraguay expresan propuestas inspiradas en el "buen vivir" de toda la población. Sin embargo, estos ejemplos de la participación de las mujeres indígenas en la política del Paraguay son espejo de problemáticas comunes a otros países vecinos con presencia indígena significativa como lo son Bolivia, Argentina y Brasil.

En el conjunto de países mencionados puede hablarse de una "indianidad latinoamericana como subalternidad", argumento este que pertenece al antropólogo peruano Ladislao Landa Vásquez, que ha opacado el reconocimiento del discurso político de los indígenas (LANDA, 2007). Esto contrasta con el creciente protagonismo indígena en la política de países como Ecuador, México y Bolivia. Guillermo Bonfil Batalla, etnólogo mexicano, reconoce que en la década de los 60 y 70 se gestó el movimiento indígena en colaboración con una antropología más crítica. Este movimiento, que unió a intelectuales y líderes indígenas, dio nacimiento al discurso indianista en la década de los 90 (BONFIL, 1981). Para tal logro, un elemento importante fue el acceso a la educación formal y cursos superiores de los indígenas, como reconoce el etnólogo brasileño Roberto Cardozo de Oliveira (CARDOZO de OLIVEIRA, 1988). Otro elemento fue la generación de antropólogos críticos como: Miguel A. Bartolomé, Nelly Arevalo de Jiménez, Guillermo Bonfil Batalla, Esteban E. Mosonyi, Víctor D. Bonilla, Darcy Ribeiro, Gonzalo Castillo C., Pedro Agostinho da Silva, Miguel Chase-Sardi, Scott S. Robinson, Silvio Coelho dos Santos, Stefano Várese, Carlos Moreira N., Georg Grünberg. Ellos han cuestionado el rol de los antropólogos indigenistas en las relaciones entre el Estado y los pueblos indígenas. Muestra de estas posiciones críticas se expresan en la "Primera Declaración de Barbados: por la Liberación del Indígena", de 30 de enero de $1971^{23}$.

Los documentos programáticos que reflejan tal cuadro son las reuniones y declaraciones de Barbados I, II y III. Estos encuentros de antropólogos e indigenistas realizados en Barbados I (1971), II (1977) y III (1993) se iniciaron en enero de 1971 con el Simposio "Fricción interétnica en América del Sur No-Andina" y contaron con la participación de antropólogos interesados en denunciar las acciones de genocidio y etnocidio que afectan a los grupos tribales de las áreas selváticas de América del Sur. En los documentos finales resultantes de la "Declaración de Barbados", se llama la atención sobre la situación de los indígenas sudamericanos responsabilizándose a los estados nacionales, a las misiones religiosas y a los antropólogos. En esa "Declaración" se reconoce que los pueblos indígenas de América tienen pleno derecho y plena capacidad para crear sus propias alternativas históricas de liberación. Puede afirmarse que esos encuentros abrieron espacios para el propio discurso de los indígenas, uno de cuyos espacios es el caso de Bolivia.

\footnotetext{
${ }^{23}$ Disponible en: http://www.servindi.org/pdf/Dec_Barbados_1.pdf Acceso en: 13 octubre 2018.
} 
Según informaciones del Instituto Nacional de Estadística (INE, 2015), Bolivia está constituida por $41 \%$ de población indígena, es decir un país con alto porcentaje de población indígena. Tal porcentaje trata de la autoidentificación/pertenencia a alguno de los 36 pueblos y 36 lenguas reconocidos en calidad de naciones indígenas por la Constitución Política del Estado del 2009. El proceso de participación política indígena abarca desde 1979 el ámbito nacional, departamental y municipal según investigadores bolivianos (CÁRDENAS et al., 2011). Tal ampliación participativa en diversas esferas se dio tras una larga historia de marginación a líderes indígenas que culminó por ganar espacios efectivos en los ámbitos parlamentarios. Ejemplo de ello tiene lugar en 1993 cuando el voto popular consagró a Víctor Hugo Cárdenas como primer Vicepresidente indígena, un intelectual aymara ${ }^{24}$. Otro marco importante y relevante para Latinoamérica tuvo lugar en 2005 cuando fue electo Evo Morales como primer Presidente de origen indígena, aymara, representando todo un giro descolonial, como señala Walter Mignolo:

(...) un giro de la izquierda en América del Sur bajo el liderazgo político, intelectual e ideológico de los movimientos indígenas que no necesitaron ni de Marx ni de Lenin para darse cuenta de que eran explotados" (MIGNOLO, 2006, p. 94).

¿Puede el subalterno hablar? Es el título del trabajo de Gayatri Chakravorty Spivak publicado originalmente en 1994 con el título en inglés "Can the Subaltern Speak". En este, Spivak cuestionaba si el subalterno - una amplia gama de la población subordinada a grupos dominantes que controlan los poderes político económico y cultural puede realmente expresarse y ser escuchado. Esta teórica india se refiere específicamente a los oprimidos, los silenciados y, sobre todo, a las mujeres. Además, aporta un elemento sensato e interesante que parte de una paradoja: si el subalterno pudiese hablar, dejaría de ser subalterno. En sus palabras, tal situación puede ocurrir si escapan de su condición de clase, género y etnia, que, sería "renunciar a la condición subalterna para alcanzar tal objetivo" (SPIVAK, 1994 apud LANDA, 2007, p. 14). Años después, en 1999, Spivak complementa que de lo que realmente carece el subalterno es de la capacidad de hablar políticamente (SPIVAK, 1999, p. 309 apud SALES, 2006, p. 23). Importante en este sentido es lograr que esa voz silenciada encuentre una vía para ser escuchada. Esto se aproxima a lo que Foucault denomina "saberes sujeitados", que refiere a ese conjunto heterogéneo de "conhecimentos silenciados pelas circunstâncias históricas estabelecidas por densas relações de poder e que foram desqualificados, desligitimados, em nome de um conhecimento verdadeiro, em nome dos direitos de uma ciência que seria possuída por alguns" (PELUCIO 2012, p. 401 apud FOUCAULT, 2005, pp. 12-13).

\footnotetext{
${ }^{24}$ Los aymaras son un pueblo amerindio y milenar que se encuentran asentados en el altiplano boliviano y peruano, en el sur de Ecuador y en el norte de Argentina y de Chile.
} 
Tomando como referencia los estudios de Ranajit Guha se puede establecer un paralelo entre los "insurgentes campesinos de la India Colonial" y los indígenas en Bolivia. Aquellos "se apoyaron en su propia actuación para recuperar su lugar en la historia" (GUHA, 1992, p. 70) y estos en su identidad indígena para recuperar su lugar en la historia. En el complejo escenario por la disputa por el poder hay una presencia de "subalternos" con voz propia, indígenas de Bolivia, que sin renunciar a su condición de clase, género y etnia han hecho escuchar su voz en la política. Una dimensión interesante de esa constatación es el lugar que ha ocupado la mujer indígena boliviana en la arena política: históricamente a ella le fueron negados esos espacios.

Excepciones en este sentido fueron el "Movimiento Sufragista" (1920-1952) y el "Movimiento Nacionalista Revolucionario" (1942) que llega al poder en 1952 con el apoyo de mineros, campesinos e indígenas, con fuerte apoyo de las mujeres (ROMÁN, 2008). Otro ejemplo atípico fue una mujer boliviana - Lidia Gueiler Tejada, haber ocupado temporalmente la presidencia del país en 1979. Sin embargo, la inclusión de la mujer indígena en la política puede caracterizarse como procesual teniendo un antecedente importante en 1952. En este año se obtuvo el sufragio sin condicionamientos, pudiendo elegir y ser electas (CÁRDENAS et al, 2011). Otros antecedentes recientes importantes son dos organizaciones con mayor incidencia en la vida pública boliviana: la Federación Nacional de Mujeres Campesinas de Bolivia "Bartolina Sisa" - de 1980, y la Federación Nacional de Trabajadoras del Hogar de Bolivia, de 1993 (MONTES, 2011, p. 220). Ambas organizaciones son parte de una Confederación Nacional de Mujeres Indígenas de Bolivia (CNAMIB), como espacio propio para las mujeres, y que representa un símbolo de liberación desde una perspectiva incluyente, vinculante a otras organizaciones indígenas, trabajando junto a ellas con y desde su propia identidad.

A partir de las elecciones de 1989, puede observarse el acceso de mujeres indígenas al Parlamento de Bolivia destacándose el caso de Remedios Loza Alvarado, indígena aymara. En 1997, por Ley $N^{\circ} 1779$ "Ley de Reforma y Complementación al Régimen Electoral" las mujeres logran la cuota de participación del 30\%. En 2004 se incluyó el sistema de paridad mediante "Ley de Agrupaciones Ciudadanas y Pueblos Indígenas" (Ley N²771/2004). Y en 2010, la "Ley del Régimen Electoral" No 026 de 2010 , fortalece la ley anterior enfatizando la paridad y agrega "la alternancia para candidaturas y la inclusión de candidatos y candidatas indígenas como estado plurinacional" (ARCHENTI y TULA, 2014, p. 61). Como se puede apreciar han existido más dispositivos legales ocupados en facilitar la presencia de la mujer en la vida política del país en las últimas dos décadas.

Desde el punto de vista constitucional la Carta Magna de 2009 explícita condiciones de igualdad entre mujeres y hombres. También en esta constitución se establecen derechos específicos ${ }^{25}$ para los pueblos

\footnotetext{
${ }^{25}$ La Carta Magna del Estado Plurinacional de Bolivia de 2009, en su Artículo 15, II y III trata de derechos específicos de las mujeres que el Estado tomará medidas necesarias para prevenir, eliminar y sancionar la violencia de género y generacional. El Artículo $45, \mathrm{~V}$ trata el derecho a la maternidad segura, con una visión y práctica intercultural y especial asistencia en los periodos prenatal y posnatal. En su Artículo 48, VI
} 
indígenas y para las mujeres, al mismo tiempo en que se incluyen los principios de paridad, alternancia e inclusión en Bolivia. Un hito importante en la participación política de mujeres indígenas bolivianas en el gobierno nacional se produjo con la designación de una indígena quechua $^{26}$ Tomasa Yarhui como "Ministra de Asuntos Campesinos y Pueblos Indígenas y Originarios" durante el período de 1997 a 2001 (ROMÁN, 2008). Otros dos ejemplos son Domitila Barrios de Chungara ${ }^{27}$, del sector minero, y la indígena quechua Silvia Lazarte quien asumió la presidencia de la Asamblea Constituyente para la redacción del texto de la Constitución Política del Estado de 2009, (VÁZQUEZ, 2006).

Desde el punto de vista electoral el Gobierno de Evo Morales (20062019), desde el Movimiento al Socialismo - Instrumento Político por la Soberanía de los Pueblos (MAS-IPSP), cambió el panorama político relacionado a las mujeres. Por ejemplo, en las elecciones de 2014 la participación política femenina fue del 52\% como diputados y del $44 \%$ en el Senado (LA RAZÓN DIGITAL, 2014) ${ }^{28}$, que la coloca en la vanguardia. Se destacan mujeres indígenas como Soledad Chapetón, aimara, Alcalde de El Alto desde 2015; María Eugenia Choque, aimara historiadora andina, recientemente nombrada Presidenta del Tribunal Supremo Electoral y las guaraníes: Delina Cumandiri, senadora y Marcia Mandepora, profesor de la Universidad Mayor de San Simón. También en dicho gobierno dos dispositivos legales se destacan para combatir el acoso y la violencia en una sociedad aún patriarcal (ONU Bolivia, 2014). Son estos los casos de la Ley No 243/2012 "Contra el Acoso y Violencia Política hacia las Mujeres" y la Ley 348/2013 "Ley Integral para Garantizar a las Mujeres una Vida Libre de Violencia".

Paralelamente, este gobierno trajo consigo el aumento de la alfabetización y capacitación de mujeres indígenas con la implementación de dos programas educativos: "Yo sí puedo"29 (2006) y "Yo sí puedo seguir" (2009). Ellos favorecieron al 70\% de las mujeres adultas campesinas indígenas, algo no visto en los gobiernos precedentes. Otros ejemplos recientes de estas conquistas sociales son los debates del "Encuentro de Mujeres"/"1 er. Encuentro de Mujeres Guaraní en Acceso y Ejercicio de la Autonomía”, en abril de 2018. La participación política de las mujeres indígenas en Bolivia no está exenta de obstáculos

\footnotetext{
asegura a las mujeres su derecho de no ser discriminadas o despedidas por su estado civil, situación de embarazo, edad, rasgos físicos o número de hijas o hijos. Además, garantiza la inamovilidad laboral de las mujeres en estado de embarazo, hasta que la/el hija/o cumpla un año de edad. Lo que respecta a los pueblos indígenas en su Capítulo IV Derechos de las Naciones y Pueblos Indígenas originarios y campesinos, Artículos 30 y 31 recogen ampliamente los derechos de los pueblos autóctonos presentes en Bolivia, asegurándoles su identidad cultural, idioma, tradición histórica, instituciones, territorialidad y cosmovisión, como también su medicina, sus conocimientos, al ejercicio de sus sistemas tradiciones políticos, jurídicos y económicos, y el derecho a la participación en los órganos e instituciones del Estado.

${ }^{26}$ Pueblo indígena que ocupa los actuales territorios de Bolivia, Ecuador, Perú, Argentina y Chile.

${ }^{27}$ Proviene del sector minero y es una referencia de la visibilidad de las mujeres bolivianas en la política campesina/indígena. Su Dispobible en: http://www.resumenlatinoamericano.org/2017/03/13/boliviamemoria-historica-video-13-de-marzo-domitila-barrios-nuestro-enemigo-principal-es-el-miedo/

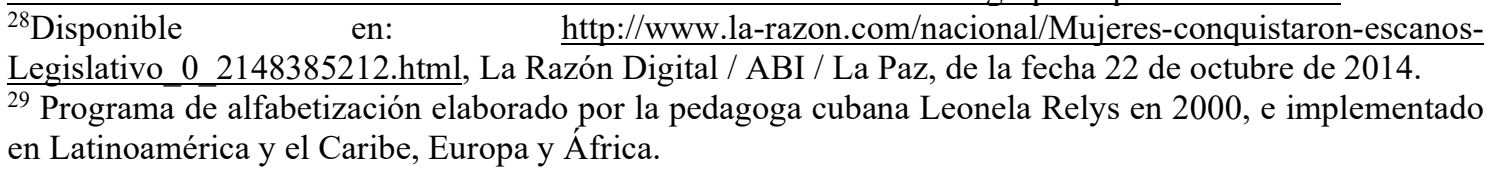


provenientes de la cultura patriarcal discriminatoria en un país con altos índices de feminicidios ${ }^{30}$. Muchas demandas y problemáticas - la maternidad y el trabajo doméstico son dos ejemplos, siguen pendientes o no han sido incorporadas "plenamente" en la política, o agenda de gobierno/estado. Dicha realidad lleva a pensar que el rol de las mujeres y su presencia en la política es un desafío a largo plazo. Veamos, más al sur, el panorama de la participación indígena y la política, en Argentina.

Hablar de género en Argentina es un tema que no escapa al cotidiano, en un país en que existe más respeto e igualdad de género. Sin embargo, esto no se aplica cabalmente a la participación política, pues ésta todavía se asocia a una "cuestión de hombres" y que según la politóloga argentina Mariana Caminotti esta exclusión "lesiona la premisa de igualdad política y atenta contra la representatividad de las instituciones" (CAMINOTTI, 2013, p. 330). En 1947 Argentina accede al voto femenino, y a partir de entonces ha continuado la lucha por los derechos. En las décadas de los 60 y 70 la participación de las mujeres cobró mayor fortaleza, expresada en una activa militancia política. Ante la dictadura militar (1976-1983), se desarrolló una práctica de sobrevivencia y hábitos de resistencia expresada en grupos como "Las Madres y Abuelas de Plaza de Mayo", dando un ejemplo de vigor y fortaleza propios de las mujeres. A partir de la reapertura democrática en 1983, se gestaron multiplicidad de grupos, y fue conformándose el "Movimiento de Mujeres en Argentina". Varias fueron las conquistas alcanzadas como la "Patria Potestad" (1985), el "Divorcio Vincular" (1987) y la "Ley de Protección contra la Violencia Familiar" (1994).

Argentina es pionera en Latinoamérica en conseguir una participación real de la mujer en la vida política. Ejemplo de ello fue, en 1991, la Ley 24.012, conocida como "Ley de Cupo Femenino", que garantiza un porcentaje de $30 \%$ para las mujeres en el parlamento (CAMINOTTI, 2014). Otro dispositivo legal importante en este sentido es de 2017. En este año se sancionó la Ley 27.412, conocida como "Ley de Paridad de Género" que estipula una presencia proporcional de mujeres y hombres para los cargos electivos y partidarios. De esta manera, las listas legislativas deberán tener, a partir de 2019 , el 50 por ciento de candidatas mujeres. Esto nos indica que habrá un cambio de panorama en relación con la política de Argentina, ya que la participación actual de mujeres en el Congreso Nacional, 2017-2019, en la Cámara baja representa solo el $37,7 \%$ del total y en el Senado está conformado con una participación del $40,3 \%$, según datos oficiales del gobierno ${ }^{31}$.

De acuerdo al Instituto Nacional de Asuntos Indígenas de Argentina (INAI) el país cuenta con 31 pueblos indígenas, hablan 13 lenguas y representan el 2,4\% de la población total de Argentina (INAI, 2015). Este país reconoce la preexistencia étnica y cultural de los pueblos aborígenes

\footnotetext{
${ }^{30}$ A pesar de la Ley 348/2013 "Ley integral para garantizar a las mujeres una vida libre de violencia", según datos de la CEPAL, Bolivia no ha reducido la tendencia de asesinatos de mujeres y la cifra se mantiene alrededor de 110 al año, equivalente a la tasa de 2.0 por cada 100.000 mujeres mayores. Disponible en: https://oig.cepal.org/es/indicadores/feminicidio Acceso en: 31 oct 2018.

${ }^{31}$ Disponible en: https://www.argentina.gob.ar/observatorioelectoral/analisis/mujeres acceso en: 18 enero 2018.
} 
en su territorio desde la Constitución 1994, específicamente, en su artículo 75 - inciso $17^{32}$. Tal reconocimiento favorece a la militancia política de las mujeres indígenas. Esa militancia política se fortalece en Argentina con la repercusión de la "IV Conferencia Mundial sobre la Mujer", celebrada en Beijing-China, 1995. Varias acciones se registraron a partir de esta conferencia internacional, una de las más importantes fue la creación del "Consejo Nacional de la Mujer Indígena" (CONAMI), en 1996 (SCIORTINO, 2015). Además otros grupos, existentes antes de Beijing, comprometidos con la defensa de los derechos de los pueblos originarios, se vieron fortalecidos como la "Confederación Mapuche Neuquina", creada en 1982. Consiguen así una mayor visibilidad ante el "Enlace Continental de Mujeres Indígenas de las Américas", sobre todo, con la presencia de Verónica Hullipan - líder mapuche. Recientemente se realizó en Buenos Aires el "1 er. Parlamento de Mujeres Originarias"33 (abril de 2018) considerado un marco importante en el camino de la construcción política y organización de los pueblos originarios. Explícitamente ellas se consideran:

\begin{abstract}
(...) protagonistas del resguardo de nuestros territorios, defendemos el arte de habitar y nuestras cosmovisiones. Nos encontramos porque nos urge proteger la vida, tejer entramados entre los Pueblos, mirarnos a los ojos y escuchar nuestros corazones, son los latidos de la tierra que nos llama al camino del Buen Vivir ${ }^{34}$.
\end{abstract}

Del ingreso de las mujeres indígenas - subalternas en su condición socio-existencial, en la vida política argentina se ocupa Andrea Gigena. Esta especialista en etnicidad y género, cita varias indígenas que ocuparon cargos políticos en los últimos años. Por ejemplo, Cilda Ofelina Santucho - la primera diputada campesina-indígena, electa en Santiago del Estero, para ejercer el cargo legislativo durante el período 2013 -2017; Rita Liempe - descendiente de mapuches, electa diputada provincial en Buenos Aires, 2011 ; Andrea Charole - electa para el Instituto del Aborigen del Chaco y a Milagros Salas - electa diputada provincial en Jujuy en 2013 (GIGENA, 2015). Las han logrado desde diversos espacios como el Frente Amplio Progresista (FAP) reemplazado actualmente por el Frente Progresistas y en el caso de Salas por el Partido por la Soberanía Popular, liderada por ella misma. Además, cuentan con mujeres líderes de sus

\footnotetext{
32 Además del reconocimiento de la preexistencia étnica y cultural de los pueblos indígenas en Argentina, el referido artículo también garantizó "el respeto a su identidad y el derecho a una educación bilingüe e intercultural; reconoce la personería jurídica de sus comunidades, y la posesión y propiedad comunitarias de las tierras que tradicionalmente ocupan; y regular la entrega de otras aptas y suficientes para el desarrollo humano; ninguna de ellas será enajenable, transmisible, ni susceptible de gravámenes o embargos. Aseguró su participación en la gestión referida a sus recursos naturales y a los demás intereses que los afectan. También otorga la jurisdicción de las provincias argentinas en relación a lo estipulado por este artículo e inciso. Disponible en: http://pdba.georgetown.edu/Parties/Argentina/Leyes/constitucion.pdf Acceso: 18 oct 2018.

33 Disponible en: https://mundo.sputniknews.com/reportajes/201711101073868812-politica-americalatina-neuquen-pueblos-indigenas/ Acceso en: 18 oct 2018.

34 Disponible em: https://ciseiweb.wordpress.com/2018/03/20/1er-parlamento-de-mujeres-originarias/ Acceso em: 17 octubre de 2018.
} 
comunidades, como el caso de Jorgelina Duarte y Juana González, Mbya Guaraní de las comunidades Tamandua y Tekoa $Y$ 'vyty de la Provincia de Misiones.

La creciente participación de mujeres que se asumen como líderes y referentes en distintas luchas y resistencias indígenas trae consigo un giro hacia la "visibilidad de la mujer indígena" (GÓMEZ, 2014, p. 69). Este giro se expresa con mayor fuerza y claridad en el Brasil. Brasil también ha sido un palco de luchas y conquistas en materia de derechos femeninos desde los novecientos. Un ejemplo temprano de tal afirmación fue la conquista del sufragio femenino, en 1932. Durante los años del "Estado Novo" (1937-1945) no se alcanzaron muchos avances en materia de derechos femeninos. Este estado se configuró como un orden social relegando a la mujer a una posición secundaria. Según argumenta la socióloga brasileña, Ana Alcántara Costa, durante el "Estado Novo" fue común relacionar a la mujer con estereotipos y virtudes domésticas y maternas. Esta tendencia fue reforzada con la creación del "Movimiento União Feminina do Brasil”, en 1935 (ALCÁNTARA, 2005, p. 3). Un papel más participativo de la mujer puede encontrarse durante el período democrático (1945-1964). En estos años, grosso modo, mujeres participan de la lucha por el fin de la violencia, salario igual para trabajo igual y guarderías públicas. Palco de esas luchas fue la "Federação das Mulheres do Brasil", creado en 1949. Con el régimen militar instaurado en 1964 los movimientos políticos femeninos fueron silenciados. Este argumento hace plantear a la teórica política Céli Pinto que "el nuevo feminismo nace de la dictadura" (0TT0, 2004, p. 239). Ejemplos de ello fue la fundación, en 1970 del "Núcleo de Estudos sobre a Mulher" en la Pontificia Universidade Católica de Río de Janeiro, por la socióloga Fanny Tabak. Su propósito fue el de cambiar patrones androcéntricos de la ciencia con aporte de la academia. Este feminismo de resistencia fue desarrollándose a partir de 1974 y profundizado hasta la actualidad (MENDES y TAIT LIMA, 2016, p. 13).

Tal es así, que a partir de 1975, declarado por la ONU como "Año Internacional de la Mujeres" se crean los grupos feministas en la región sudeste del Brasil, en las ciudades de São Paulo y en Río de Janeiro. Esos grupos fueron: "Centro da Mulher Brasileira" (CMB) y la "Sociedade Brasileira para o Progreso de la Ciência" (SBPC). Además surge al sur de Brasil, Estado de Paraná, la revista feminista "Brasil Mulher" (1975) y "Nós Mulheres" (1976) (MARQUES y ZATTONI, 2014, p. 58). Para finales de las década de 1970 dieron inicio los "Encuentros Feministas Nacionales" que han sido realizados de forma consecutiva hasta el presente. A partir de aquel, los movimientos feministas alcanzaron otras instancias políticas como sindicatos, partidos y movimientos comunitarios. Las críticas principales fueron dirigidos al sistema patriarcal, a las prácticas y mentalidades sexistas y machistas. Ellas adquieren una mayor visibilidad con la primera plataforma "Alerta Feminista", de 1982, con reivindicaciones más consistentes como: igual salario por trabajo igual, derecho a licencia de maternidad, control de natalidad, guarderías para niños y restaurantes populares. 1985 fue un año icónico, pues en él se promulga la Ley n 7.353 que crea el "Conselho Nacional dos Direitos da 
Mulher" (CNDM). Vinculado al Ministerio de Justicia este promueve políticas públicas contra la discriminación de la mujer y trabaja en pro de asegurar la participación femenina en la vida política, económica y cultural del país. Este movimiento nacional se desdobló en la creación de similares consejos en los ámbitos estadual y municipal (RODRÍGUEZ, 2004).

Brasil ha avanzado en temas de género, mas no de manera proporcional en participación política femenina. De acuerdo con la politóloga María Inés Tula desde 1997 cuenta con un 30\% de cuota establecido por la Ley No 9.504/1997, para la participación de mujeres en la arena política (TULA, 2015). Sin embargo, el porcentaje actual de diputadas y senadoras corresponde al $15 \%$ y al $12,9 \%{ }^{35}$ respectivamente, cifras que demuestran lo lejos que están de alcanzar lo estipulado por la ley citada. En relación a los indígenas, su población, de acuerdo al censo del Instituto Brasileño de Geografía y Estadísticas (IBGE, 2010), corresponde al $0,47 \%$ de la población total del país, con 305 pueblos y 274 lenguas habladas (Figura 3).

Figuras 3: Guarani Kaiowá em defesa do território, Mato Grosso do Sul - Brasil,

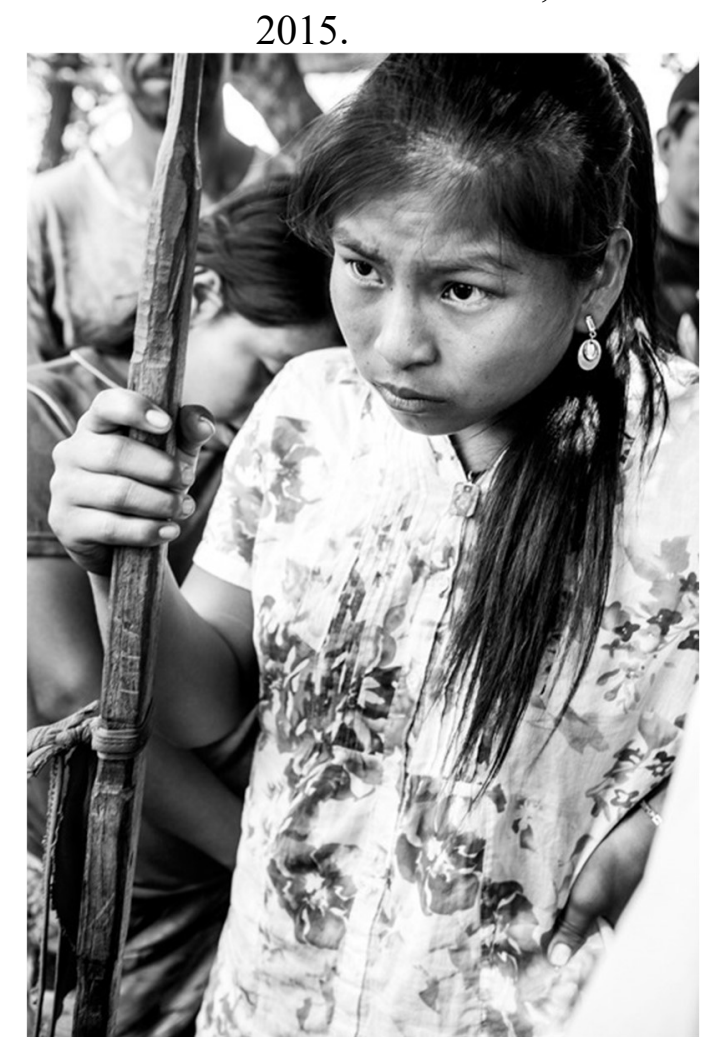

Fuente: Fotografía de Rogério Ferrari ${ }^{36}, 2015$.

\footnotetext{
${ }^{35}$ Disponible en: https://ultimosegundo.ig.com.br/politica/2018-10-08/mulheres-eleitas-congresso.html Acceso en: 13 nov 2018.

${ }^{36}$ Rogério Ferrari de Souza, destacado fotógrafo brasileño, doctorando en antropología cuya investigación es sobre los Mbya Guaraní de Misiones, Argentina. Desde 2001 realiza fotografías y proyecto de Antropología visual "Existências-Resistências", que consiste en el registro y la publicación de libros sobre pueblos y movimientos que luchan por la autodeterminación, tales como en los campos de refugiados del Líbano y de Jordania de Palentina; Curdos de Turquía; Sahrauis de los campos de refugiados de Argelia y territorios ocupados por Marruecos; Zapatistas de México; Guaranis Kaiowa de Mato Grosso do Sul; Ava Guaraní y Mbya Guaraní de Paraguay y Argentina; pueblos indígenas y ciganos de la Bahía - Brasil. Es
} 
En las décadas de 1980 y 1990 las mujeres indígenas de Brasil crean sus propias organizaciones o departamentos de mujeres dentro de las organizaciones existentes, sobre todo en la Amazonia Brasileña. Entre tales organizaciones de mujeres indígenas más antiguas se cuentan con Organização das Mulheres Indígenas de Roraima (OMIR) creada en 1986 y la Associação de Mulheres Indígena do Alto Rio Negro (AMARN), creada en 1987. En los años noventa fue realizado el Primer Encuentro de Mujeres Indígenas, en Maturuca/TI Raposa Serra do Sol (1996), donde las indígenas asumen los siguientes compromisos: "la lucha por la tierra y la autosustentabilidad, la revitalización de la cultura, continuación del proyecto de costura y el combate al alcoholismo" (SACCHI, 2003, p. 97). Contar con sus territorios tradicionales les garantiza la sobrevivencia de sus pueblos y el derecho a la salud y educación diferenciadas.

De acuerdo a la "Comisión ONU Mujeres Brasil" (2017) ${ }^{37}$, el proyecto "Voz de las Mujeres Indígenas" realizó un trabajo con 22 líderes para la construcción de una "Agenda Nacional de las Mujeres Indígenas". Los puntos fundamentales de lucha política fueron: el "enfrentamiento a la violencia contra las mujeres y otras formas de opresión contra los pueblos indígenas, empoderamiento y participación político-económica; el derecho a la salud, educación, seguridad, tierra y conocimientos tradicionales" (ONU Brasil, 2017). En tales movimientos ganaron protagonismo líderes indígenas como Sonia Bone Guajajara, del pueblo Guajajara perteneciente a la familia lingüística tupi-guaraní. Sonia Guajajara una de las mayores lideresas indígenas y coordinadora ejecutiva de la "Articulación de los Pueblos Indígenas de Brasil". También fue candidata a vice-presidenta del Brasil, para disputar las elecciones presidenciales 2018 por Partido Socialismo e Liberdade (PSOL). Una importante victoria para las mujeres indígenas en las elecciones de octubre de 2018 fue la elección de la diputada federal Joenia Batista de Carvalho $^{38}$ - del pueblo Wapichana y primera mujer indígena en graduarse en derecho en Brasil, representando al estado de Roraima, desde el Partido Rede Sustentabilidade ${ }^{39}$.

Otro ejemplo importante lo representa Rita Gomes do Nascimento, profesora y doctora en Educación, indígena del pueblo Potiguara. Gomes do Nascimento ha sido la primera mujer que asumió la dirección de políticas de educación a nivel Ministerio, en el campo indígena para las Relaciones etno-raciales. Desde 1986 está en servicio público y ha accedido a instancias importantes de decisión política desde 2010. Desde

autor de varios libros como: "Parentes. Povos indígenas na Bahia" (2018); "Ciganos" (2011); Sahraouis (2010); "Palestine" (2008); Curdos. Uma Nação Esquecida (2007); "Zapatistas - A velocidade do Sonho" (2006); Palestina. A Eloquência do Sangue (2004).

37 Disponible en http://www.onumulheres.org.br/areas-tematicas/lideranca-e-participacao/, Acceso en fecha $08 / 02 / 2018$.

${ }^{38}$ Disponible en: http://www.resumenlatinoamericano.org/2018/10/10/brasil-estamos-escribiendo-nuestrahistoria-dice-primera-mujer-indigena-elegida-diputada/ Acceso en: 14 octubre de 2018.

39 Rede de Sustentabilidade (REDE) es un partido político fundado por la ecologista y pedagoga brasileña Marina Silva, en 2013. En línea: http://www.redesustentabilidade.org.br/ Acceso: 29 marzo 2019. 
ese palco traba una batalla importante en el ámbito de la educación y en beneficio de los pueblos indígenas, como Consejera de la "Cámara de Educación Básica del Consejo Nacional de Educación” (CNE/CEB), Miembro del "Colegio de Culturas Indígenas del Consejo Nacional de Políticas Culturales" (CNPC) del Ministerio de Cultura (MinC) y miembro, de la "Comisión Nacional de Educación Escolar Indígena" (CNEEI). Otro palco, más local de liderazgo indígena femenino, lo son las aldeas urbanizadas: conformadas por comunidades que han migrado a la ciudad al ser enajenados sus territorios ${ }^{40}$.

En este nuevo espacio, la participación de Ivanice Piris Tanoné, del pueblo Kariri Xocó, ha alcanzado una dimensión importante a partir de su militancia política. En otro ámbito local, de esta vez municipal, Brasil también cuenta con la participación política de mujeres indígenas en el ámbito municipal. En este varias son las concejales indígenas como Daiane Vilhnarva ${ }^{41}$, guaraní y recientemente nombrada Secretária Assistência Social en la Prefeitura de Japorã, Estado Mato Grosso do Sul. Precisamente de este estado brasileño proviene un testimonio reivindicatorio de la militancia indígena. Y es relatado por Rosely Stefanes, al referirse a mujeres Guaraní Kaiowá de Mato Grosso do Sul. Ellas, según esta antropóloga brasileña, expresan:

Hoje a nossa luta, o nosso grito é pela demarcação de nossas terras tradicionais, pois, dela fomos expulsos obrigados a viver confinados em Reservas Indígenas com espaço limitados, o que nos resta é viver amontoado em minúsculos espaços de terra, isso nos expõe a vários problemas sociais que atingem e desestruturam o nosso povo Guarani e Kaiowá. (Documento Final V Kuñangue Aty Guasu Assembleia das Mulheres Kaiowa e Guarani, en Estado de Mato Grosso do Sul, 2017:, p. 1), (STEFANES, 2017, p. 108).

Aún lo avances son tímidos si se compara con el espacio a ser ocupado en un país donde las políticas públicas son pensadas y ejecutadas a partir de una óptica occidental y masculina (STEFANES y STEFANES, 2013). Todavía existen comunidades de pueblos indígenas sin territorios (Kaiowa, Mbya Guaraní, Terena, Guaraní Nhandeva) y sin acceso a las necesidades básicas. Mujeres indígenas guaraníes como Edelmira Pérez y Santa Alves - ambas de la comunidad Ocoy ${ }^{42}$, tienen claro que la participación política tiene por objetivo último la recuperación de

\footnotetext{
${ }^{40}$ Un estudio actualizado sobre las aldeas urbanizadas indígenas en el Brasil es de autoría de Adir Casaro Nascimento y de Carlos Magno Naglis Viera y se titula "O índio e o espaço urbano: breves considerações sobre o contexto indígena na cidade", publicado en 2015.

${ }^{41}$ Disponible en: http://www.sejusp.ms.gov.br/wp-content/uploads/sites/21/2015/01/LISTA-GESTORES20156.pdf, acceso en: 8 febrero 2018 .

${ }^{42}$ Entrevistas con la líder indígena de la Comunidad Educativa y la "jar'yi” (abuela sabia). Ocoy es una comunidad indígena de los Ava Guaraní Paranaenses de San Miguel de Yguaçu, Estado de Paraná, donde fueron agrupados de diferentes comunidades de las orillas del Paraná, en 1982, para la construcción de la represa binacional de Itaipú.
} 
sus territorios, la defensa de los derechos humanos y de la naturaleza. Vale subrayar que la reivindicación de territorios ancestrales es necesaria, ya que sin territorio el ejercicio de otros derechos, no es posible, como el derecho al desarrollo de su cultura, del idioma, de la espiritualidad y de la organización social que posibilite las condiciones de vida dignas por el buen vivir de sus pueblos.

\section{Consideraciones finales}

Para presentar y/o resumir, a modo de conclusiones, las ideas centrales de este artículo hemos seguido el orden expositivo de los dos epígrafes que lo conforman: "Ma ê pyahu kuña ypykuérare" y "Kuña ypykuéra ojepytaso polítikape". Ante todo, el hecho de esos subtítulos estar escritos en guaraní, también traducidos al español, revela la familiaridad de los autores con la población interlocutora del artículo: las mujeres indígenas del Sur Amerindio, especificamente, las mujeres indígenas guaraníes de Argentina, Bolivia, Brasil y Paraguay.

En relación al primer epígrafe "Ma`ê pyahu kuña ypykuérare"/"Nuevas miradas a las mujeres indígenas" fue realizado un levantamiento sobre estudios que reorientan nuestra comprensión sobre los pueblos indígenas de la América del Sur. Aún de forma más específica esas producciones deconstruyen estereotipos existentes sobre el papel de las mujeres indígenas en la historia y cultura Guaraní evitando así interpretaciones reduccionistas y binarias aún presentes en los medios académicos de los países hispano-hablantes. Desde el punto de vista académico, un denominador común de esas producciones científicas es su interdisciplinariedad. La bibliografía que fundamenta este primer epígrafe proviene de la antropología, de la sociología, de la etnografía y de la historia. Una parte considerable de las fuentes bibliográficas son de autoría de investigadoras como Rita Segato, Mariana Goméz, Branislaba Súsnik, Beate Lenher, Florencia Roulet, Cristina Wolff junto a otros investigadores como Bartomeu Meliá, Roger Bartra, Aníbal Quijano y Guillermo Wilde, por citar los más importantes en este artículo. Ese conjunto de autores recolocan nuestras comprensiones del universo indígena en tópicos específicos como la relación doméstico y público, la organización matrilocal y el dualismo de género en los pueblos indígenas. En este primer epígrafe hay una imagen que corresponde al "Mapa Continental Guaraní". Publicado en 2016 este mapa fue producto de un trabajo minucioso de campo sobre los pueblos guaraníes por parte de varios especialistas, uno de los cuales es la autora principal de este artículo.

En este artículo hay otras dos imágenes, ellas corresponden al último epígrafe "Kuña ypykuéra ojepytaso polítikape". Ambas imágenes son expresión de diversas realidades del universo guaraní en el Sur Amerindio. La figura del número 2, del lente fotográfico de Claudia Cáceres, representa una "jarýi" - símbolo de sabiduría y longevidad guaraní. Por su vez, la figura del número 3 - cortesía del fotógrafo y 
antropólogo brasileño Rogério Ferrari, tiene un poder de evocativo relacionado a las luchas de los pueblos indígenas guaraníes por su territorio en el Mato Grosso, Brasil. Precisamente, un relato crítico, reivindicatorio y comparado sobre la incursión en la política de mujeres indígenas guaraníes ocupa gran parte del segundo epígrafe "Participación política de las mujeres indígenas". Anticipa este relato un resumen bibliográfico y perspectivas teóricas sobre "género" del cual nos interesa la dimensión social de la que este concepto es portador y la crítica realizada por diversos autores (Jane Collier, Michelle Rosaldo, Louise Lamphere) a modelos interpretativos que subordinan a las mujeres en los ámbitos públicos y privados. Aún más, estudios de género contemporáneos (Silvana Sciortino, Mariana Gómez, Camila Gómez) ubicados más allá del discurso moderno occidental han reconocido la ausencia de una estructura jerárquica en los pueblos indígenas revelando diversos lugares y posiciones ocupados por la mujer indígena en sus culturas.

Un ejercicio interesante de reflexiones en la segunda parte de este artículo es la comprensión del género en países como Paraguay, Bolivia, Argentina y Brasil. No pocos especialistas coinciden sobre el protagonismo y visibilidad de las mujeres indígenas en sus comunidades. Aún más allá, a partir de especialistas como Bartomeu Meliá y Raquel Peralta descubrimos el liderazgo femenino Guaraní, secularmente no tan visible por su particularidad y diferencia del liderazgo femenino no indígena. La solución al problema de la inclusión de las mujeres - de cuyo relato pormenorizado también se ocupa el segundo epígrafe de este artículo - en la política en el Sur Amerindio va más allá de promover leyes e implementar mecanismos para cumplirlas. Para llegar a este fin se hace necesario un cambio en las estructuras partidarias que integre y reconozca a la mujer como actor político capaz y secular: "Kuña Pyrenda", de Paraguay; "Rede Sustentabilidade", de Brasil; "Movimiento al Socialismo", de Bolivia y "Frente Amplio Progresista", de Argentina. La actuación de ellos apunta un camino interesante para viabilizar la participación de las mujeres indígenas en la vida política de países sudamericanos. 


\section{Referencias bibliográficas}

ALCANTARA COSTA, Ana Alice. O movimento feminista no Brasil: dinâmicas de uma intervenção política. Universidad Autónoma de Madrid, p. 1- 20, 2005.

ARCHENTI, Nélida y TULA, María Inés. Cambios normativos y equidad de género. De las cuotas a la paridad en américa latina, los casos de Bolivia y Ecuador. América Latina Hoy, Universidad de Salamanca, v., 66, p. 47-68, 2014.

ARGENTINA. Constitución de la Nación Argentina. Buenos Aires: Corte Suprema de Justicia de la Nación / Biblioteca del Congreso de la Nación / Biblioteca Nacional, 2010.

BARTRA, Roger. El mito del salvaje (Primera edición FCF). México: Fondo de Cultura Económica, 2011.

BÁRCENA DÍAZ, Leticia. La mujer gobernante en la época prehispánica. Vida Científica, Universidad Autónoma de Hidalgo.

BONFIL BATALLA, Guillermo. Utopía y revolución. El pensamiento político contemporáneo de los indios en América Latina. México: Editorial Nueva Imagen, 1981.

BOLIVIA. Ley de régimen electoral N026/2010. Estado Plurinacional de Bolivia. Constitución política del Estado Plurinacional de Bolivia (2009).

BRASIL. CONSTITUIÇÃO DA REPÚBLICA FEDERATIVA DO BRASIL. São Paulo: Goberno do estado de Saô Paulo, 2018.

CÁCERES GONZÁLEZ, Claudia; MORO GUTIÉRREZ, Lourdes y PENA CASTRO, María José. Resiliencia sociocultural de los Mbya Guaraní de Paraguay en contextos de desarraigo y relocalización territorial. Temas Antropológicos, Yucatán, v. 39, n. 2, p. 85-104, set. 2017.

CAMINOTTI, Mariana. Ideas, legados y estrategias políticas en la reforma de las reglas de selección de candidatos: La Ley de cuotas pionera de Argentina. Revista Uruguaya de Ciencia Política, Montevideo, vol. 23, dic. 2014

CAMINOTTI, Mariana. La representación política de las mujeres en el período democrático. Sociedad Argentina de Análisis Político, v. 7, n. 2, p. 329-337, nov. 2013.

CÁRDENAS, V. H., Fernando, A., JOUANNET, A., PADILlA, G., MALDONADO, L., JIJÓN, V. H., SOBERANIS, C., REYES, F., OSPINA, J. y SALMÓN, E. Participación Política Indígena y Políticas Públicas para Pueblos Indígenas en América Latina. La Paz: Garza Azul, 2011.

CARDOSO DE OLIVEIRA, Roberto. A crise do Indigenismo. Campinas: Editora da Unicamp, 1988. 
Espaço Ameríndio

CASARO NASCIMENTO, Adir y NAGLIS VIEIRA, Carlos Magno. O índio e o espaço urbano: breves considerações sobre o contexto indígena na cidade. Cordis. História: Cidade, Esporte e Lazer, São Paulo, n. 14, p. 118-136, jan./jun. 2015.

CHKRAVORTY SPIVAK, Gayatrik e SANTIAGO, Giraldo. ¿Puede hablar el subalterno? Revista Colombiana de Antropología, Bogotá, v. 39, p.297-364, dic. 2003.

COLLIER, Jane (1974). Women in Politics. En: ROSALDO, Michelle and LAMPHERE, Louise (eds). Women, Culture \& Society. California: Standford University Press, pp. 89-96.

ENRIZ, Noeli. Un sueño blanco: reflexiones sobre la educación Mbyá-guaraní en Argentina. Amazônica, Pará, 2 (1), 28-44, 2010.

FAÚNDEZ MELÉNDEZ, Alejandra y WEINSTEIN CAYUELA, Marisa. Guía para incorporar enfoque de género en la gestión pública con población indígena. DF México: ONU Mujeres, 2011.

FERNANDES, Catarina Costa. Os Guarani Mbya a manutenção de sua cultura a través do currículo como política social e cultural. Tesis de Doutorado. Universidad del Norte, Ciudad del Este - Paraguay, 2006.

FEDERACIÓN NACIONAL DE MUJERES CAMPESINAS DE BOLIVIA "BARTOLINA SISA". Plan Estratégico de la FNMCB "BS" (2008-2017). La Paz: Estrategia de País, 2008.

FILÁRTIGA, Joel y AGUERO WAGNER, Luis. Apocalipsis. Imperialismo ecológico y ecoapocalipsis global. Asunción: Fundación Joel Filártiga, 2004.

FOUCAULT, Michel. Em defesa da sociedade: Curso no Collège de France (19751976). São Paulo: Martins Fontes, 2005.

GARCIA, Dorotea. Entrevista a la Takuajary, sabia abuela de 88 años de la comunidad Arroyo Mokôi, Canindeyú - Paraguay, julio 2017.

GIGENA LAVETTI, Andrea I. Participación política de mujeres indígenas-campesinas en Santiago del Estero (Argentina): huellas de feminismo en los márgenes. Entramados y perspectivas, Buenos Aires, v. 5, n.5, 65-88, set.2015.

GÓMEZ, Mariana y SCIORTINO, Silvana (comps). Mujeres indígenas y formas de hacer política: un intercambio de experiencias situadas en Brasil y Argentina. 1a ed. Temperley, Buenos Aires: Tren en Movimiento, 2018.

GOMES, Camilla de Magalhães. Gênero como categoria de análise decolonial. Civitas, Porto Alegre, v. 18, n. 1, p. 65-82, jan.-abr. 2018

GÓMEZ, Mariana D. Mujeres indígenas en Argentina: escenarios fugaces para nuevas prácticas políticas. Publicar, Buenos Aires, v. 12, n.16, p.59-81, jun. 2014. 
Espaço Ameríndio

GUARDIA, Sara Beatriz. Historia de las Mujeres en Latinoamérica. Segunda edición. México: CEMHAL, 2013.

GUHA, Ranajit. Elementary aspects of Peasant Insurgency in Colonial India. Oxford University Press, Delhi, 1992.

HERNÁNDEZ GARCÍA, Yuliuva. Acerca del género como categoría analítica. Nómadas, n.13. Publicación electrónica de la Universidad Complutense, 2006.

HERNÁNDEZ ASTETE, Francisco. La coya en la organización del Tahuantinsuyo. In: Guardia, Sara Beatriz. Historia de las Mujeres en Latinoamérica. México: CEMHAL, 2013, p. 23-35.

INSTITUTO NACIONAL DE ASUNTOS INDÍGENAS DE ARGENTINA. Derechos de los pueblos indígenas en la Argentina. Demicheli C., Sebastián, Canet. Viviana, Virosta Leticia. (Comps). 1ra. Edic. Buenos Aires: Secretaría de Derechos Humanos, 2015.

INSTITUTO BRASILEIRO DE GEOGRAFÍA E ESTADÍSTICA (IBGE), 2018.

LAMAS, Marta. Diferencias de sexo, género y diferencia sexual. Cuicuilco Nueva Época, DF México, v. 7, n. 18, p.1-24, 2000.

LAMPHERE, Louise (1993). The domestic sphere of women and the public world of Men: The strehgths and limitations of an Anthropological dichotomy. En: Brettell, Caroline, Carolyn y F. Sargent (eds). Gender in cross-cultural perspective. New York: Prentice Hall, pp. 67-77.

LANDA VÁSQUEZ, Ladislao. Los Fantasmas de la Subalternidad (La transformación de/en los discursos (sobre los) indígenas en América Latina). TOMO, Revista de Núcleo de Pos-graducao e Pesquisa en Ciencias Sociales - Universidade Federal de Sergipe, n.11, p. 9-41, dic. 2007.

LARA ANDRADE, Isi Verónica y LARA ROMERO, Lily. Papel de las Mujeres Indígenas en México. Quest Journals Journal of Research in Humanities and Social Science, v. 5, n. 6, p. 73-77, 2017.

LEHNER, Beate. Los Pueblos Guaraní del Paraguay Oriental. Asunción: Misereor, 2005 .

MANDEPORA Chundary, Marcia. Estrategias de interculturalización de la gestión educativa de la UNIBOL “Apiaguaiki tûpa”. En: Navarro, Mónica. Entre la práctica y la teoría. Aportes para la construcción de una gestión educativa intra e intercultural en Bolivia, Cochabamba, 2016, pp 204-224.

MAPA GUARANÍ CONTINENTAL - EMGC. Campo Grande, MS, 20016.

MARTINEZ, Delia. Entrevista a la Takuajary y Profesora de la comunidad Ara Pyahu, Canindeyú - Paraguay, junio 2018. 
Espaço Ameríndio

MARQUES, Ana Maria y ZATTONI, Andreia Marcia. FEMINISMO E RESISTÊNCIA: 1975 - o centro da mulher brasileira e a revista veja. História Revista, Goiânia, v. 19, n. 2, p. 58 79, 2014.

MELIÁ, Bartomeu. Camino Guaraní, Guaraní Rape. De lejos venimos, hacia más lejos caminamos. Mombyrygui niko jaju, mombyryvénte ko jaguata. Asunción: Cepag, 2016.

Pueblos de la nación Guaraní del Paraguay actual. 2014.

El guaraní experiencia religiosa. Asunción: CEADUC - CEPAG, 1991.

. Educación indígena y alfabetización. Asunción: CEPAG, 2009.

MENDES DE VASCONCELLOS, Bruna y TAIT LIMA, Márcia Maria. Fanny Tabak e os primeros passos dos Estudos sobre a Ciência, Tecnologia e gênero no Brasil. REDES, Bernal, v. 22, n. 43, p. 13-32, dic. 2016.

MIGNOLO, Walter D. Evo Morales en Bolivia: ¿giro a la izquierda o giro descolonial? In: DA CRUZ, José. Democracias en desconfianza. Ensayos en sociedad civil y política en América Latina. Montevideo: Coscoroba, 2006, p. 93-106.

MONEY, John y TUCKER, Patricia. Asignaturas sexuales. Barcelona: A.T.E., 1978

MONTES, Tania. Las organizaciones sociales de las mujeres indígenas y su relación con la política formal. Ciencia y Cultura, La Paz, n. 26, p. 231-237, jun. 2011.

MORAES, Marilda; BRUNO, Garcia y SUTTANA, Renato. Educação, diversidade e fronteiras da in/exclusão. Dourados, MS: Editora da UFGD, 2012.

NÚÑEZ,Yamila Irupé. Educación superior e interculturalidad en Misiones-Argentina. Textos\&Debates, Boa Vista, n.21, pp. 59-74, jan./jun. 2012.

ONU Mujeres. Igualdad de género y principales brechas en Paraguay. Taborga, Carolina (Cood.). Asunción: AGR, 2015.

OLIVERA, Mercedes. Discriminación de género y etnia. In: BONFIL, Paloma y MARTÍNEZ, Elvia R. Diagnóstico de la discriminación hacia las mujeres indígenas. México: Comisión Nacional para el Desarrollo de los Pueblos Indígenas, 2003, p. 171197.

OTTO, Claricia. O feminismo no Brasil: suas múltiplas faces $\mathrm{O}$ feminismo no Brasil: suas múltiplas faces Uma história do feminismo no Brasil. PINTO, Céli Regina Jardim. Estudos Feministas, Florianópolis, v. 12, n. 2, p. 237-253, agost. 2004.

PARAGUAY. Constitucion de la República del Paraguay (1992).

Paraguay.

. LEY 904/81 (1981). Estatuto de las Comunidades Indígenas. Asunción, 
Espaço Ameríndio

PELÚCIO, Larissa. Subalterno quem, cara pálida? Apontamentos às margens sobre póscolonialismos, feminismos e estudos queer. Contemporânea - Revista de Sociologia da UFSCar. São Carlos, v. 2, n. 2, p. 395-418, jul-dez, 2012.

PERALTA, Raquel. Entrevista a la Antropóloga paraguaya a efecto de la investigación, enero, 2018.

PEREIRA DE SOUZA, Lady Day y BANDEIRA CEMIN, Arneide. Mulheres indígenas em Porto Velho: Gênero, migração e participação política. Fazendo Gênero 9 Diásporas, Diversidades, Deslocamentos, Universidade Federal de Santa Catarina, p. 1-9, 2010.

PUEBLOS INDÍGENAS EN EL PARAGUAY. Resultados finales de Población y Viviendas. III Censo Nacional de Población y Viviendas para Pueblos Indígenas (2012), Censo 2012. Fernando de la Mora: DGEEC, 2014.

QUIJANO, Aníbal. Colonialidad del poder, eurocentrismo y América Latina. In: LANDER, Edgardo (comp.) La colonialidad del saber: eurocentrismo y ciencias sociales. Perspectivas Latinoamericanas. CLACSO, Consejo Latinoamericano de Ciencias Sociales, Buenos Aires, 2000, p. 201-246.

REITER, Rayna (1975). Toward an Anthropology of Woman. New York: Monthly Review Press.

RODRIGUES, Almira. Participação Política das Mulheres e Gestão em Política de Gênero. Políticas para Mulheres. Palestra en I Conferência Distrital de Políticas para Mulheres, Brasília, 26 a 28 de maio de 2004.

ROULET, Florencia. La resistencia de los Guaraní del Paraguay a la conquista española (1537-1556). Posadas: Editorial Universidad Nacional de Misiones, 1993.

ROMÁN ARNES, Olivia. Participación política y liderazgo de las Mujeres Indígenas en America Latina. Estudio de caso Bolivia. Cochabamba: PNUD en México, 2008.

ROSALDO, Michelle (1979). Mujer, cultura y sociedad: una visión teórica. En: Harris, Olivia y Kate Young (comps.). Antropología y feminismo. Barcelona: Editorial Anagrama, pp. 153-181

ROSALDO, Michelle and LAMPERE, Louise (eds.) (1974). Women, Culture \& Society. California: Standford University Press.

RUBIN, Gayle. El tráfico de mujeres. Notas sobre la "economía política del sexo". Nueva Antropología, DF México, v. 8, n. 30, p. 95-145, nov. 1986.

SACCHI, Ângela. Mulheres indígenas e participação política: a discussão de gênero nas organizações de mulheres indígenas. Anthropológicas, Recife, ano 7, v. 14, p. 95-110, 2003.

SALES SALVADOR, Dora. Traducción, género y poscolonialismo. Compromiso traductológico como mediación y affidamento femenino. Quaderns. Revista de 
Espaço Ameríndio

traducció, Universitat Jaume I de Castelló Departament de Traducció, Castelló, n. 13, p. 21-30, 2006.

SANTOS, Anabella. O movimento feminista no processo de formualzao das politicas publicas de enfrentameitno da violencia doméstica contra la mujer, p. 61-106, 2011. Pontificia Universidad Católica de Rio de Janeiro.

SEGATO, Rita Laura. Gênero e colonialidade: em busca de chaves de leitura e de um vocabulário estratégico descolonial. e-cadernos ces, Coimbra, 2012.

SARAIVA, Marcia P. Identidade multifacetada: a reconstrução do ser indígena entre os Juruna do médio Xingu. Belém: NAEA, 2008.

SOTO, Lilian. Partidos políticos y participación política de las mujeres en Paraguay. Elementos para el debate. Asunción: Centro de Documentación y Estudios (CDE), 2015.

$\overline{\text { Gráficos, } 2014 .}$

Mujeres Indígenas y Política en Paraguay. Asunción: Servicios

SUSNIK, Branislava. El indio colonial del Paraguay. Asunción: Museo Etnográfico Andrés Barbero, 1965.

SCIORTINO, Silvana. Procesos de organización política de las mujeres indígenas en el movimiento amplio de mujeres en Argentina. Consideraciones sobre el feminismo desde la perspectiva indígena. Universitas Humanística, Bogotá, n. 79, p. 65-87, jun. 2015.

STEFANES PACHECO, Rosely, y STEFANES PACHECO, Isabela. La actuación de la mujer indígena guaraní kaiowá en las reinvindicaciones territoriales. Iconos, Quito, n. 45, p. 25-39, ener. 2013.

STEFANES PACHECO, Rosely A. Mulheres indígenas e participação política: emergência étnica feminina em um contexto de expropriação territorial. Religación, Quito, v. 2, n.8, p. 101-114, dic. 2017.

SPIVAK, Gayatry. "Can the Subaltern Speak" In: WILLIAMS, Patrick and Chrisman, Laura. Colonial Discourse and Post-Colonial Theory, A Reader, New York: Columbia University Press, 1994.

SPIVAK, Gayatri Chakravorty (1988). «Can the subaltern speak?». En: WILLIAMS, Patrick y Laura CHRISMAN (eds.), Colonial Discourse and Post-Colonial Theory. A Reader. Hertfordshire: Prentice Hall/Harvester Wheatsheaf, 1993, p. 66-111.

TARRÉS, María Luisa. A propósito de la categoría género: leer a Joan Scott. Estudios Sociológicos, DF México, v. 31, n.91, p. 3-26, abr. 2013.

TULA, María Ines. Mujeres y política. Un panorama sobre la adopción de las cuotas de género y sus efectos en América Latina y Colombia. Opera, v.16, p. 9-33, jun. 2015. 
Espaço Ameríndio

TRINIDAD SANABRIA, Lino. ÑE'ÊNDY RAITY. Ñe'êryru - Nuevo Diccionario Ilustrado Guaraní - Castellano / Castellano - Guaraní. Mbo’éhára ha temimbo'e rembiporurâ. Asunción: Fondec, 2008.

VILLALBA, Sara Mabel. Entrevista a la Politóloga, investigadora y Profesor, a efecto de la investigación, jun. 2018.

VÁZQUEZ, Mariano. "Entrevista a Silvia Lazarte, presidenta de la Asamblea Constituyente. Soy una mujer indígena, de pollera, campesina, neta, originaria". Fondo Documental/Narrativas de Mujeres Indígenas/ FLACSO/ Ecuador. Sucre: Edición digital. 2006.

VENEGAS DELGADO, Hernán Maximiliano y VENEGAS MARCELO, Hernán. "Indígenas, bandeirantes y fronteras coloniales ibéricas en América". Projeto História, São Paulo, n. 59, p. 137-169, jul. 2017.

WILDE, Guillermo. Religión y poder en las misiones de guaraníes. Buenos Aires: SB, 2009 .

WOLFF, Cristina Scheibe. Mulheres da floresta: uma história do Alto Juruá, Acre (1890-1945). São Paulo: Hucitec, 1999.

Recebido em: 04/04/2019* Aprovado em: 28/11/2019* Publicado em: 30/12/2019 